\title{
Caractérisation des systèmes enzymatiques protéolytiques de deux souches psychrotrophes isolées de laits crus réfrigérés
}

\author{
par \\ MILLIERE (J. B.)* et VEILLET-PONCET (L.)**
}

Les bactéries psychrotrophes regroupent de nombreuses espèces qui dégradent activement la caséine lors du stockage au froid des laits crus (Juffs et Madsen [29], Lacrosse [39], Mikawa et Hoshino [50], Miller et Kandler [51], Pürshel et Pollack [63], Sandvick et Fossum [64], Storgards et Lindqvist [67], Thomas et Thomas [70]) et sont à l'origine d'accidents en fabrication et de mauvaise conservation des produits laitiers en général. La plupart des chercheurs s'accordent à montrer que le genre Pseudomonas et plus particulièrement l'espèce $P$. fluorescens constituent la flore psychrotrophe caséolytique dominante. De nombreuses études ont été consacrées à l'étude de la protéolyse du lait et des produits laitiers par cette espèce (Babel [5], Kielwein [30], Knaut [35], Knaut et Bruderer [36], Kozlova [38], Mickelsen et al. [57], Skean et Overcast [65], White et Marshall [73], Yanagiya et al. [74]) ; son système enzymatique protéolytique a été partiellement purifié et caractérisé, mais de nombreux résultats divergent (Hoshizio [22], Hurley et al. [23], Juffs [26], Juffs et al. [28], Malik et Swanson [46], Mayerhofer [47], Mayerhofer et al. [48], Mayerhofer et al. [49], Newton [58], Peterson et Gunderson [62]).

Nous nous proposons, après avoir isolé de cinquante échantillons de laits crus réfrigérés provenant de la région de Nancy [52, 53] une flore caséolytique et psychrotrophe essentiellement constituée de bactéries élaborant un pigment caroténoïde orange, appartenant au genre Cytophaga (Gavini et Leclerc [21], et de P. fluorescens, de caractériser et de comparer les systèmes enzymatiques protéolytiques des deux souches élaborant les protéases les plus actives, Cytophaga $20 \mathrm{C} 2$ et $P$. fluorescens $28 \mathrm{P} 12$.

* I.U.T. de Biologie Appliquée - 54600 Villers-les-Nancy.

** Laboratoire de Microbiologie Alimentaire, E.N.S.A.I.A.-I.N.P.L., 32, rue SainteCatherine - 54000 Nancy. 


\section{MATERIEL ET METHODES}

\section{Origine des souches retenues}

P. fluorescens 28 P 12 et Cytophaga 20 C 2 ont été sélectionnés, en fonction de leur caractère psychrotrophe et de leur activité protéolytique, d'un lot de 996 souches isolées de cinquante échantillons de lait cru réfrigéré, collectés dans la région de Nancy. Les clones sont repiqués tous les mois sur un milieu gélosé nutritif (composition en $\mathrm{g} / 1$ : bactocasitone 5 ; extrait de levures 2,5 ; glucose 1 ; lait écrémé $5 \mathrm{ml}$; agar 15 ; pH 6,6-7,0) et stockés à $+4^{\circ} \mathrm{C}$.

\section{Production et purification partielle des protéases}

Des essais préliminaires nous permettent de définir les conditions de culture et le pourcentage de saturation en sulfate d'ammonium pour l'obtention du système enzymatique brut. 51 de lait écrémé UHT, restérilisé à $115^{\circ} \mathrm{C}$ pendant $10 \mathrm{mn}$, sont ensemencés avec $20 \mathrm{ml}$ d'une dilution au $1 / 10$ de la culture de $P$. fluorescens $28 \mathrm{P} 12$, de $18 \mathrm{~h}$ à $25^{\circ} \mathrm{C}$, en bouillon à l'extrait de levures, dont la turbidité a été préalablement ajustée à 0,220 à $540 \mathrm{~nm}$ (population initiale : $5,5.10^{4}$ bactéries par $\mathrm{ml}$ ). La souche de Cytophaga $20 \mathrm{C} 2$ présentant une activité protéolytique moindre est ensemencée à un taux dix fois plus important, ce qui correspond à une concentration bactérienne dans le lait de $4,8.10^{5}$ bactéries par $\mathrm{ml}$.

Les cultures sur lait de P. fluorescens et de Cytophaga sont incubées pendant $120 \mathrm{~h}$ à, respectivement, 20 et $30^{\circ} \mathrm{C}$, dans un bain d'eau thermostaté, sans agitation. L'élimination du culot bactérien est obtenue par centrifugation à $15000 \mathrm{~g}$ pendant $20 \mathrm{mn}$ à $+4^{\circ} \mathrm{C}$ (centrifugeuse Beckman, Spinco L2-65).

Le surnageant acellulaire additionné de $\mathrm{SO}_{4}\left(\mathrm{NH}_{4}\right)_{2}$ jusqu'à 50 p. 100 de saturation est laissé au repos pendant $24 \mathrm{~h}$ à $+4^{\circ} \mathrm{C}$, puis l'extrait enzymatique recueilli par centrifugation à $4^{\circ} \mathrm{C}(30000 \mathrm{~g}$ pendant $30 \mathrm{mn}$ ) est mis en suspension dans un minimum d'eau distillée.

Une première dialyse est effectuée pendant $48 \mathrm{~h}$ contre cinquante fois son volume en eau distillée, à la température de $1,5^{\circ} \mathrm{C}$, puis l'extrait enzymatique brut est dialysé à nouveau pendant $48 \mathrm{~h}$ à $1,5^{\circ} \mathrm{C}$ contre quarante fois son volume en tampon de Jenness et Koops [24], solution dont la composition minérale est identique à celle du lait. Les dialysats sont ensuite lyophilisés dans un appareil expérimental Froidlabo et la poudre obtenue est stockée à l'abri de l'humidité à $4^{\circ} \mathrm{C}$, pendant plusieurs semaines, sans perte d'activité.

\section{Dosage des protéines}

Après réhydratation appropriée de l'extrait enzymatique brut lyophilisé, la concentration en protéines est déterminée selon la 
méthode de Lowry modifiée [42], avec le réactif de Folin et Ciocalteu (Merck). La sérum-albumine bovine (Merck) est utilisée comme protéine-étalon.

\section{Dosage de l'activité protéolytique}

L'activité protéolytique a été étudiée sur caséine d'Hammarsten (Merck).

\subsection{Réaction enzymatique}

A $2 \mathrm{ml}$ de caséine à $2 \mathrm{p} .100$, en tampon TRIS- $\mathrm{HCl} 0,1 \mathrm{M}, \mathrm{pH}$ 7,8 , contenant $0,005 \mathrm{M}$ de $\mathrm{CaCl}_{2}$, est ajouté $1 \mathrm{ml}$ d'extrait enzymatique (ces deux suspensions sont préalablement maintenues en bain d'eau à $42^{\circ} \mathrm{C}$ pendant 2 à $3 \mathrm{mn}$ ). Après agitation et incubation à $42^{\circ} \mathrm{C}$, pendant des durées déterminées, la réaction est arrêtée par addition de $6 \mathrm{ml}$ de T.C.A. 0,3 N. Après $15 \mathrm{mn}$ de repos, le mélange est filtré sur filtre Laurent $n^{\circ} 1$ et la concentration en produits d'hydrolyse de la caséine, solubles dans le T.C.A., est déterminée selon la méthode de Lowry modifiée, à $700 \mathrm{~nm}$.

L'unité d'activité protéolytique est définie comme la quantité d'enzyme qui libère l'équivalent de $1 \mu \mathrm{g}$ de tyrosine par ml d'extrait enzymatique et par mn, dans les conditions précédemment indiquées, par référence à une courbe-étalon établie à partir de concentrations croissantes en L-tyrosine (Serva).

Un essai à blanc, dans lequel l'extrait enzymatique est ajouté après l'addition du T.C.A., est effectué pour chaque essai.

\subsection{Choix de la concentration en extrait enzymatique}

Des concentrations croissantes en extrait enzymatique, de 5 à $50 \mathrm{mg}$ par $\mathrm{ml}$, sont réalisées en réhydratant le lyophilisat avec de l'eau distillée. L'hydrolyse de la caséine isoélectrique à 2 p. 100 , à $42^{\circ} \mathrm{C}$, est déterminée après les durées de réaction s'échelonnant entre 5 et $60 \mathrm{mn}$.

Pour l'étude du système enzymatique de $P$. fluorescens $28 \mathrm{P} 12$, nous retenons une concentration de $15 \mathrm{mg}$ par $\mathrm{ml}$ et un arrêt de l'hydrolyse de la caséine après $10 \mathrm{mn}$ de réaction. Comparativement, le système enzymatique de Cytophaga $20 \mathrm{C} 2$ étant moins actif, nous choisissons une concentration de $37,5 \mathrm{mg}$ par $\mathrm{ml}$ et une durée de $60 \mathrm{mn}$.

\section{Détermination de l'activité coagulante}

L'activité coagulante est déterminée par la mesure du temps nécessaire à la coagulation d'un lait reconstitué selon Berridge [9] et dans des conditions définies. $12 \mathrm{~g}$ de lait écrémé (marque LesaffreNormandie) sont dissous pendant $20 \mathrm{mn}$ dans $100 \mathrm{ml}$ de solution de $\mathrm{CaCl}_{2} 0,01 \mathrm{M}$, puis le lait est gardé au repos pendant $1 \mathrm{~h}$ à $25^{\circ} \mathrm{C}$. Après maintien du lait et de la solution enzymatique en bain d'eau à 
$35^{\circ} \mathrm{C}$ pendant $5 \mathrm{mn}, 1 \mathrm{ml}$ d'extrait est ajouté à $10 \mathrm{ml}$ de lait. La rotation du tube immergé permet la formation d'un film homogène sur la paroi et le temps de coagulation (en $\mathrm{mn}$ et $\mathrm{s}$ ) est atteint dès qu'apparaissent les premières particules de caillé.

\section{Etude de la dégradation de la caséine par électrophorèse en gel de polyacrylamide en tube}

La protéolyse de la caséine, lors de la culture sur lait des souches

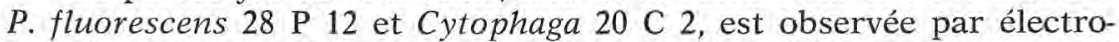
phorèse en gel de polyacrylamide en tube. L'électrophorèse est réalisée selon Ornstein (1964) et Davis (1964) dans des gels à 7 p. 100 d'acrylamide contenant de l'urée (concentration finale $6 \mathrm{M}$ ), en tampon TRIS-Glycine $0,1 \mathrm{M}, \mathrm{pH} 8,3$. Le volume de l'échantillon à analyser est de $6 \mu \mathrm{l}$ par gel. La migration est réalisée sous $2 \mathrm{~m}$ A par gel, pendant $2 \mathrm{~h}$, en utilisant comme indicateur de front de migration le bleu de bromophénol, dans un appareil (marque Canalco) contenant six tubes de verre de $7 \times 0,5 \mathrm{~cm}$.

Les protéines, après achèvement de l'électrophorèse, sont révélées par coloration, pendant $1 \mathrm{~h}$ au moins, avec une solution de noir amido, puis l'excès de colorant est totalement éliminé, par passages successifs des gels dans des bains à 7 p. $100(\mathrm{~V} / \mathrm{V})$ en acide acétique. Les diagrammes d'électrophorèse sont obtenus à l'aide d'un photomètre intégrateur enregistreur de marque Vernon.

\section{RESULTATS}

\section{Activité protéolytique}

\subsection{Influence de la concentration en caséine}

Pour les deux souches étudiées, l'activité protéolytique, à $42^{\circ} \mathrm{C}$, atteint rapidement un maximum pour des concentrations en caséine supérieures ou égales à 2 p. 100 (fig. 1).

\subsection{Influence de la température}

1.2.1. Température optimale d'activité protéolytique.

L'hydrolyse de la caséine à 2 p. 100 montre que les systèmes enzymatiques protéolytiques des deux souches se comportent d'une manière sensiblement identique vis-à-vis de la température de réaction, car les vitesses d'hydrolyse sont maxima entre 42 et $44^{\circ} \mathrm{C}$ (fig. $2 \mathrm{~A}$ et $2 \mathrm{~B}$ ).

A $20^{\circ} \mathrm{C}$, l'activité protéolytique est loin d'être négligeable puisqu'elle représente entre 30 et 40 p. 100 de l'activité maxima. Pour des températures supérieures ou égales à $45^{\circ} \mathrm{C}$, l'inactivation thermique de ces deux systèmes est très rapide et devient totale à $50^{\circ} \mathrm{C}$, ce qui semble dénoter une grande thermolabilité des protéases de $P$. fluorescens $28 \mathrm{P} 12$ et de Cytophaga $20 \mathrm{C} 2$. 


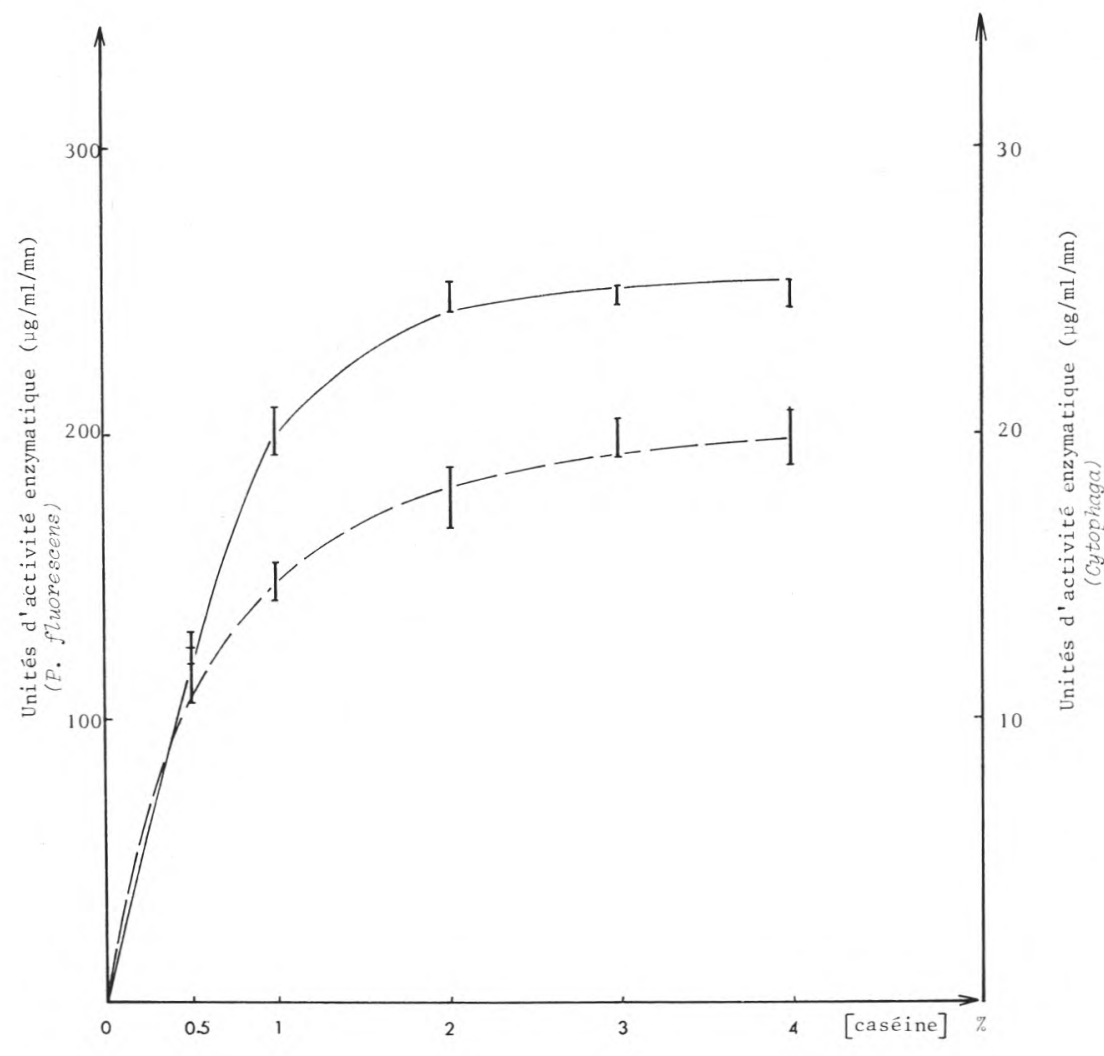

fig. 1

Activité enzymatique $(\mu \mathrm{g} / \mathrm{ml} / \mathrm{mn})$ en fonction de la concentration en substrat

- Système enzymatique de $P$. fluorescens LCM 28 P 12.

-... Système enzymatique de Cytophaga LCM $20 \mathrm{C} 2$ (moyennes de quatre essais).

\subsubsection{Stabilité thermique.}

Les extraits enzymatiques sont stables pour des températures inférieures à $40^{\circ} \mathrm{C}$. Comme l'indiquent les figures $3 \mathrm{~A}$ et $3 \mathrm{~B}$, l'extrait enzymatique de Cytophaga $20 \mathrm{C} 2$ est toutefois moins thermosensible que celui de $P$. fluorescens 28 P 12, car l'inactivation thermique des protéases de $P$. fluorescens commence à se manifester dès la température de $40^{\circ} \mathrm{C}$, alors qu'après $60 \mathrm{mn}$ à $43^{\circ} \mathrm{C}$, celle de Cytophaga est 


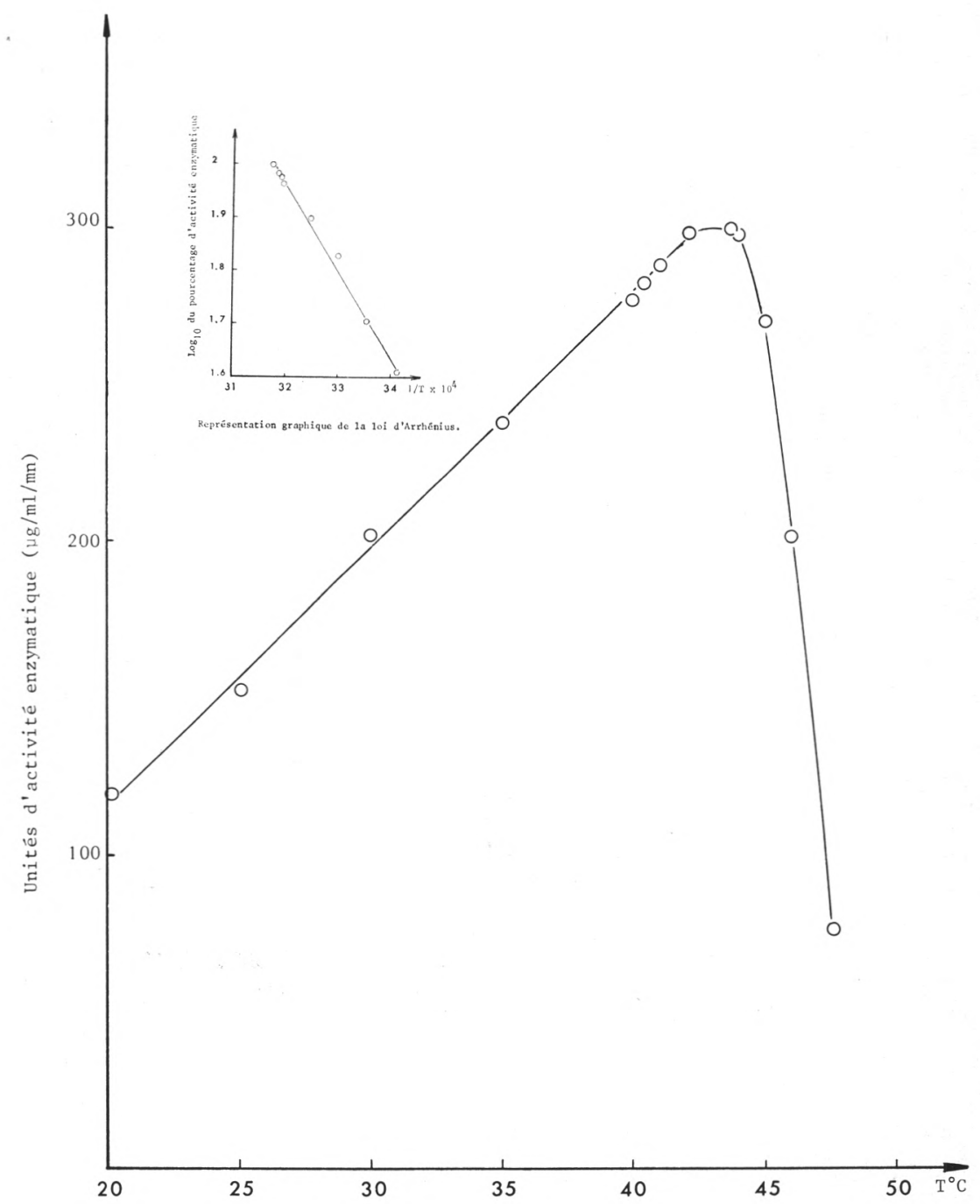

fig. 2 A

Activité protéolytique $(\mu \mathrm{g} / \mathrm{ml} / \mathrm{mn})$ du système enzymatique de $P$. fluorescens LCM $28 \quad \mathrm{P} 12$ en fonction de la température (durée de réaction $10 \mathrm{mn}$, extrait enzymatique contenant $15 \mathrm{mg} / \mathrm{ml}$ de protéines ; moyennes de cinq essais). 


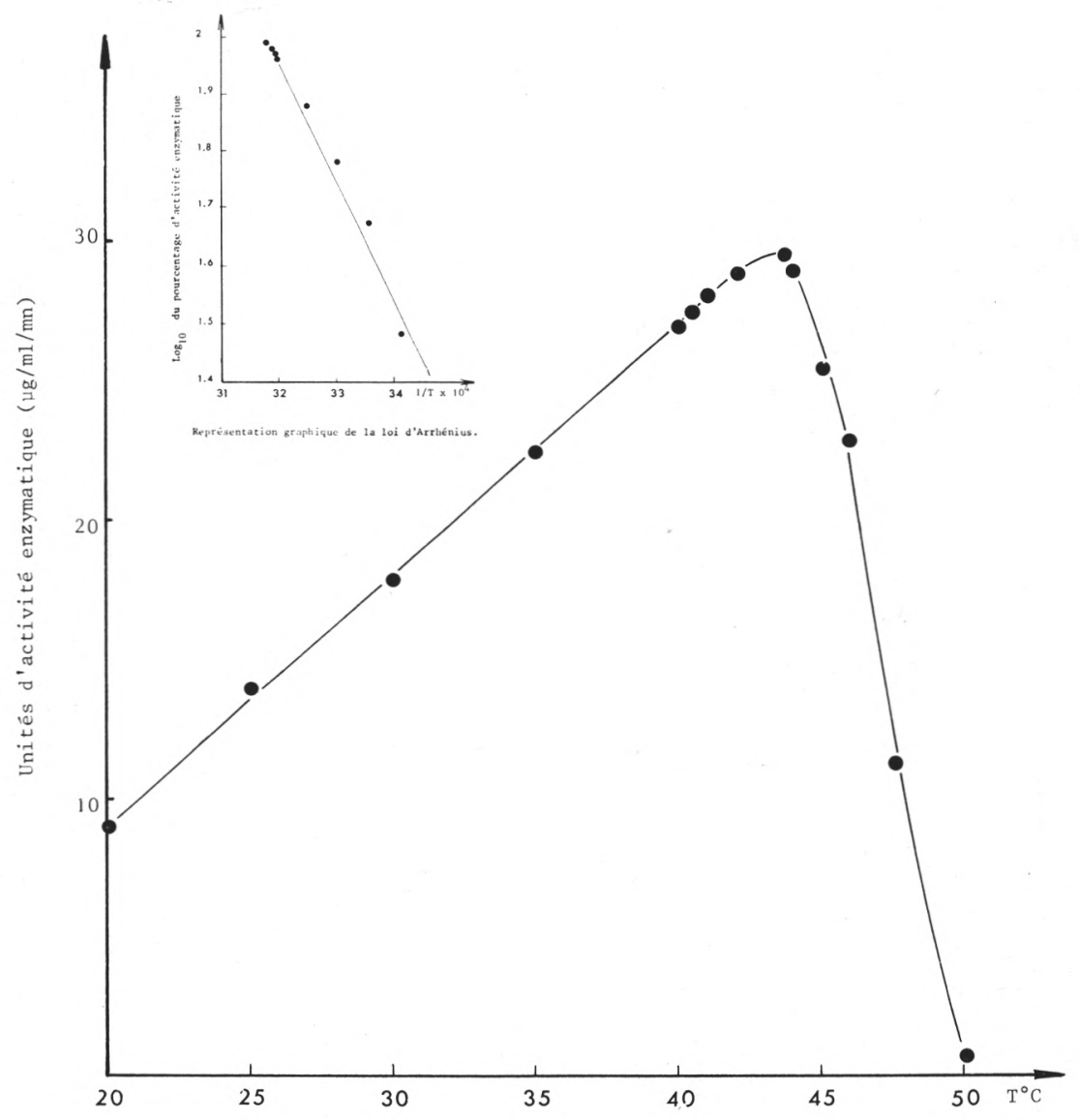

fig. $2 B$

Activité protéolytique $(\mu \mathrm{g} / \mathrm{ml} / \mathrm{mn})$ du système enzymatique de Cytophaga LCM $20 \mathrm{C} 2$ en fonction de la température (durée de réaction : $60 \mathrm{mn}$, extrait enzymatique contenant $37,5 \mathrm{mg} / \mathrm{ml}$ de protéines ; moyennes de cinq essais). 


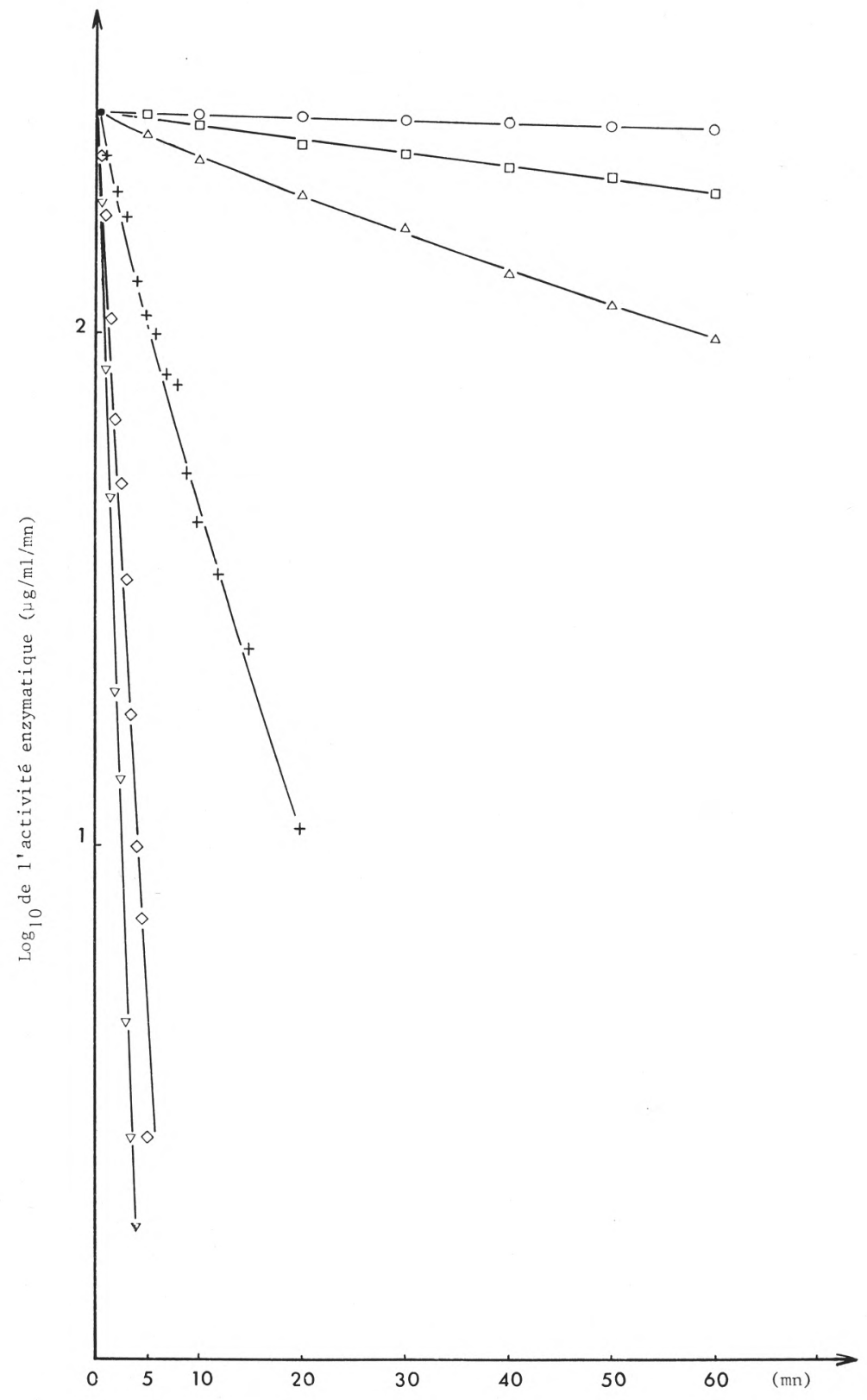

fig. $3 \mathrm{~A}$

Logarithme décimal de l'activité enzymatique $(\mu \mathrm{g} / \mathrm{ml} / \mathrm{mn})$ pour les protéases de $P$. fluorescens en fonction de la durée de chauffage $(\mathrm{mn})$ à différentes températures : $\mathrm{O} 40^{\circ} \mathrm{C} ; \square 42^{\circ} \mathrm{C} ; \triangle 43^{\circ} \mathrm{C} ;+45^{\circ} \mathrm{C} ; \diamond 47,5^{\circ} \mathrm{C} ; \nabla 50^{\circ} \mathrm{C}$ (moyennes de trois essais). 


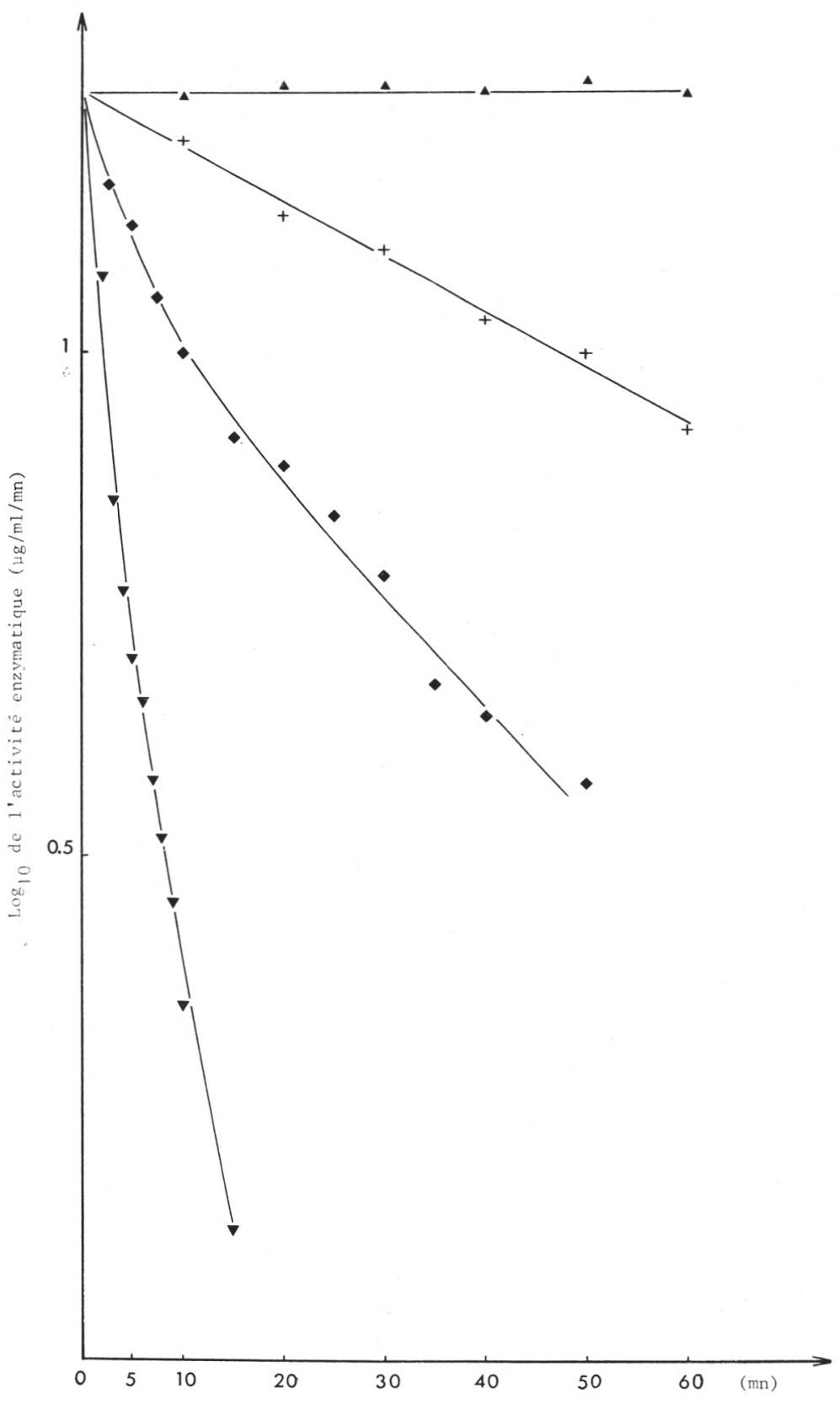

fig. $3 B$

Logarithme décimal de l'activité enzymatique $(\mu \mathrm{g} / \mathrm{ml} / \mathrm{mn})$ pour les protéases de Cytophaga en fonction de la durée de chauffage $(\mathrm{mn})$ à différentes températures : $\Delta 43^{\circ} \mathrm{C}$; $+45^{\circ} \mathrm{C}$; $47,5^{\circ} \mathrm{C} ; \boldsymbol{\nabla} 50^{\circ} \mathrm{C}$ (moyennes de trois essais). 


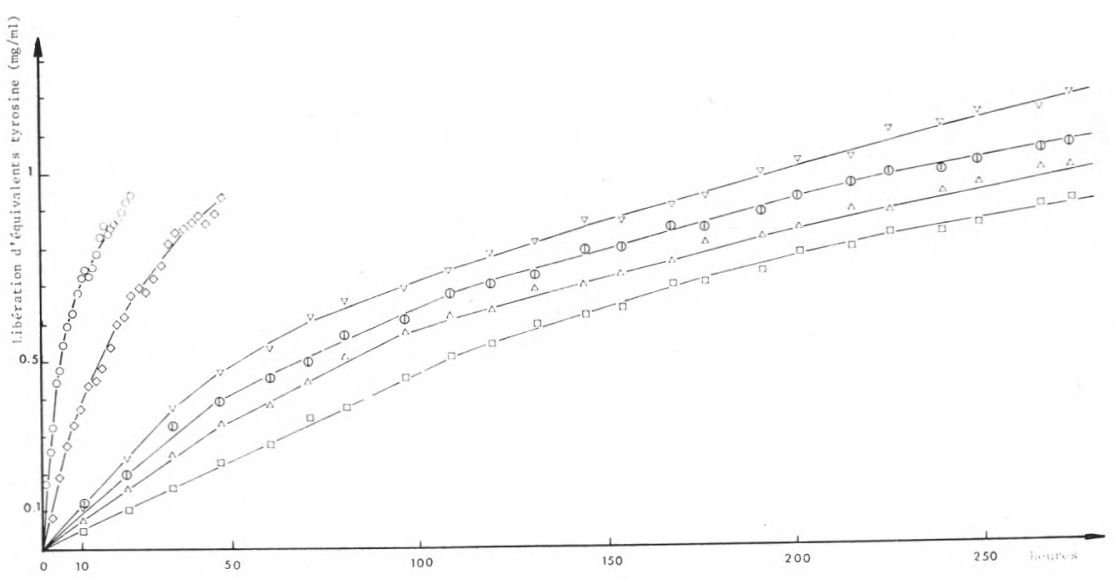

fig. 4 A

Protéolyse du lait écrémé par le système enzymatique de $P$. fluorescens LCM $28 \mathrm{P} 12(0,75 \mathrm{mg}$ d'extrait/ml de mélange réactionnel) lors du stockage à différentes températures : $\square 2^{\circ} \mathrm{C} ; \triangle 5^{\circ} \mathrm{C} ; \mathbb{\Delta} 7^{\circ} \mathrm{C} ; \nabla 10^{\circ} \mathrm{C} ; \diamond 25^{\circ} \mathrm{C} ; 042^{\circ} \mathrm{C}$.

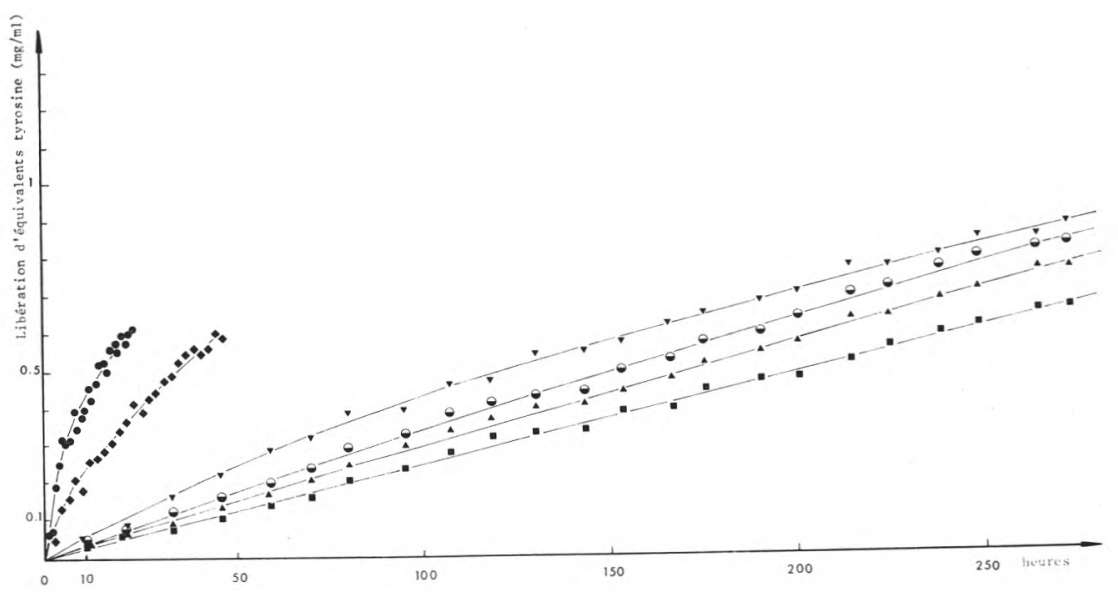

fig. $4 B$

Protéolyse du lait écrémé par le système enzymatique de Cytophaga LCM 20 C 2 $(1,5 \mathrm{mg}$ d'extrait par $\mathrm{ml}$ de mélange réactionnel) lors du stockage à différentes températures : $2^{\circ} \mathrm{C} ; \boldsymbol{\Delta} 5^{\circ} \mathrm{C} ; \bullet 7^{\circ} \mathrm{C} ; \boldsymbol{\nabla} 10^{\circ} \mathrm{C} ; \bullet 25^{\circ} \mathrm{C} ; \bullet 42^{\circ} \mathrm{C}$. 
encore nulle. Après $10 \mathrm{mn}$ de chauffage à $45^{\circ} \mathrm{C}$, les activités protéolytiques résiduelles sont respectivement de 18 p. 100 et 89 p. 100 pour les extraits de $P$. fluorescens et de Cytophaga et après $2 \mathrm{mn}$ à $50^{\circ} \mathrm{C}$, de 8,2 p. 100 et de 64,7 p. 100 .

\subsubsection{Activités aux températures de réfrigération.}

$0,6 \mathrm{~g}$ d'extrait enzymatique de $P$. fluorescens (ou 1,2 $\mathrm{g}$ pour Cytophaga), réhydraté dans $400 \mathrm{ml}$ d'eau distillée, est soumis à une filtration stérilisante sur filtre Seitz $(\varnothing 0,45 \mu), 300 \mathrm{ml}$ de solution enzymatique sont additionnés à $500 \mathrm{ml}$ de lait U.H.T. (restérilisé pendant $10 \mathrm{mn}$ à $115^{\circ} \mathrm{C}$ ), et le mélange est réparti à raison de $5 \mathrm{ml}$ en tubes stériles $220 \times 20$. Les températures d'incubation retenues sont $2,5,7,10,25$ et $42^{\circ} \mathrm{C}$.

Entre 2 et $25^{\circ} \mathrm{C}$, les activités protéolytiques des deux systèmes enzymatiques se comportent d'une manière identique, en montrant une même adaptabilité au froid. Même à $2^{\circ} \mathrm{C}$, l'hydrolyse de la caséine est loin d'être négligeable puisqu'elle correspond à 5 p. 100 environ de celle mesurée dans les conditions optimales $\left(42^{\circ} \mathrm{C}\right.$ ) (fig. 4 A et 4 B).

\subsection{Influence $d u p H$}

Les extraits enzymatiques protéolytiques des deux souches présentent une activité maxima à $\mathrm{pH} 7,0$, à la température de $42^{\circ} \mathrm{C}$, en tampon Phosphate ou en tampon TRIS- $\mathrm{HCl} 0,05 \mathrm{M}$. A pH 6, en tampon citrate- $\mathrm{NaOH}$, l'activité résiduelle est encore notable, 72 p. 100 pour $P$. fluorescens et 76,4 p. 100 pour Cytophaga. En revanche, pour des $\mathrm{pH}$ basiques, $\mathrm{pH} 8,5$, cette activité résiduelle ne représente plus que respectivement 19 p. 100 et 42 p. 100 de l'activité maximale (fig. $5 \mathrm{~A}$ et $5 \mathrm{~B}$ ).

Dans le lait frais ( $\mathrm{pH} 6,4-6,6)$, ces enzymes conservent une activité protéolytique importante, supérieure ou égale à 90 p. 100 .

\section{Activité coagulante}

\subsection{Influence de la concentration en extrait enzymatique}

Les mesures des activités coagulantes de dilutions successives, en $\mathrm{H}_{2} \mathrm{O}$ distillée, d'une solution enzymatique de $P$. fluorescens $28 \mathrm{P} 12$ (30 mg par $\mathrm{ml}$ ), montrent que la vitesse d'apparition des particules de caillé est proportionnelle à la concentration de la solution enzymatique (fig. 6).

\subsection{Activité en fonction de la température}

Avec l'élévation de la température, l'activité coagulante des solutions de $15 \mathrm{mg}$ par $\mathrm{ml}$ ( $P$. fluorescens) ou de $60 \mathrm{mg}$ par $\mathrm{ml}$ (Cytophaga) d'extraits enzymatiques augmente progressivement jusqu'à une limite au-delà de laquelle l'apparition des flocons de caséine est très forte- 


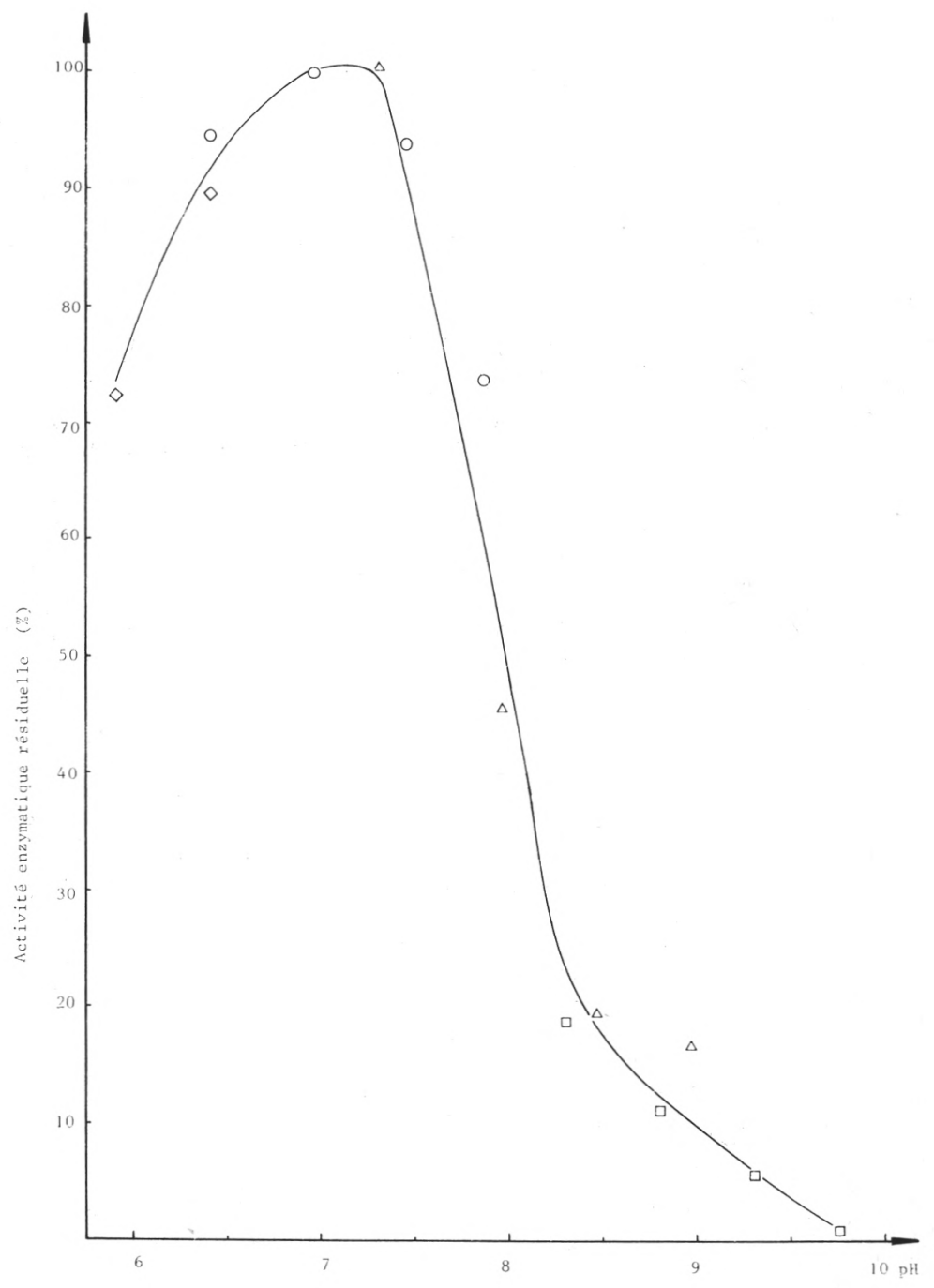

fig. $5 \mathrm{~A}$

Activité protéolytique résiduelle du système enzymatique de $P$. fluorescens LCM $28 \mathrm{P} 12$ en fonction du $\mathrm{pH}$ de la réaction.

Tampons utilisés : $[0,05 \mathrm{mM}] \diamond$ citrate ; O phosphate ; $\triangle$ TRIS-HCl ; $\square$ borate. 


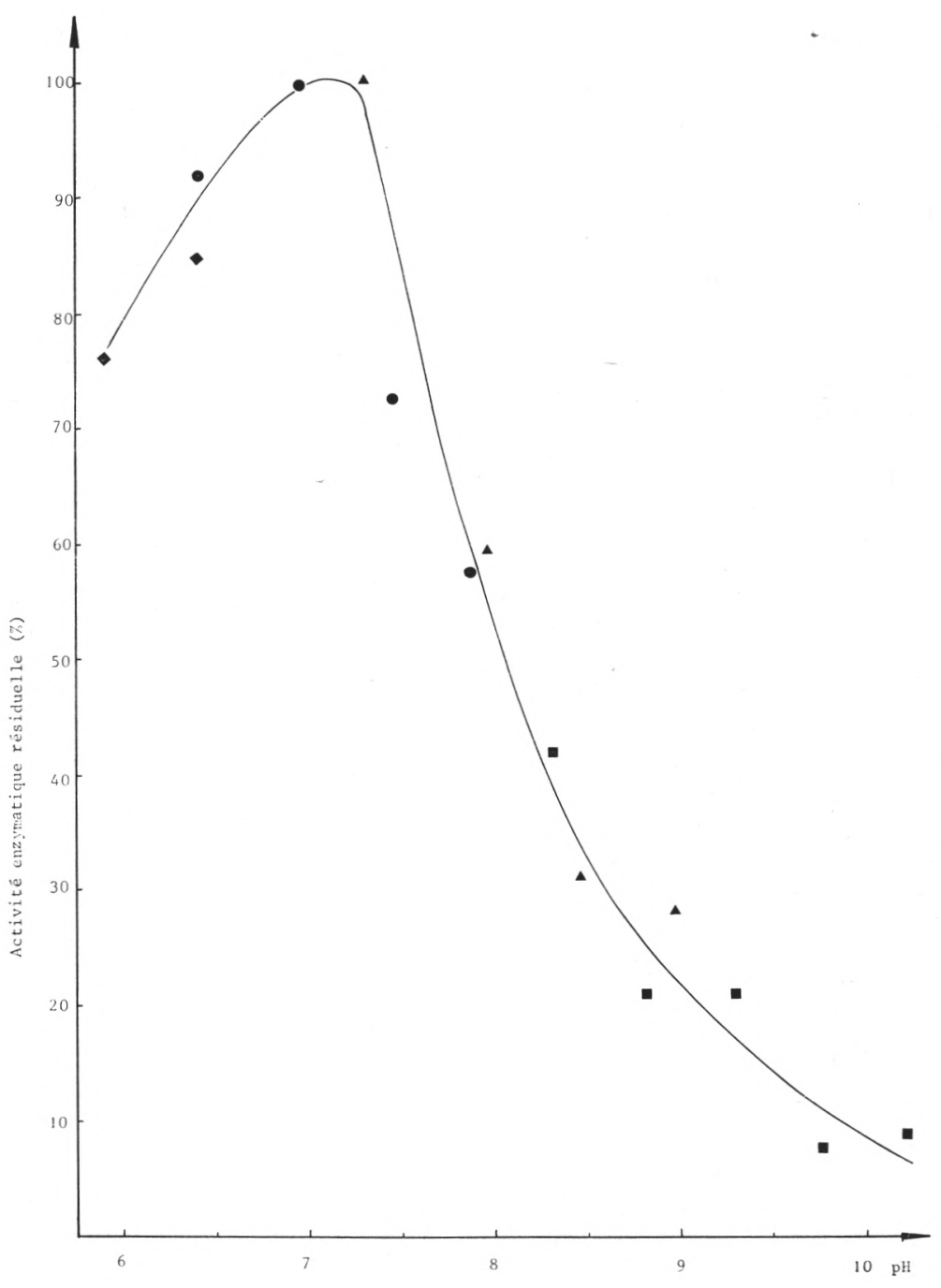

fig. $5 B$

Activité protéolytique résiduelle du système enzymatique de Cytophaga LCM 20 C 2 en fonction du $\mathrm{pH}$ de la réaction.

Tampons utilisés : [0,05 mM] citrate ; • phosphate : $\Delta$ TRIS-HCl : - borate. 


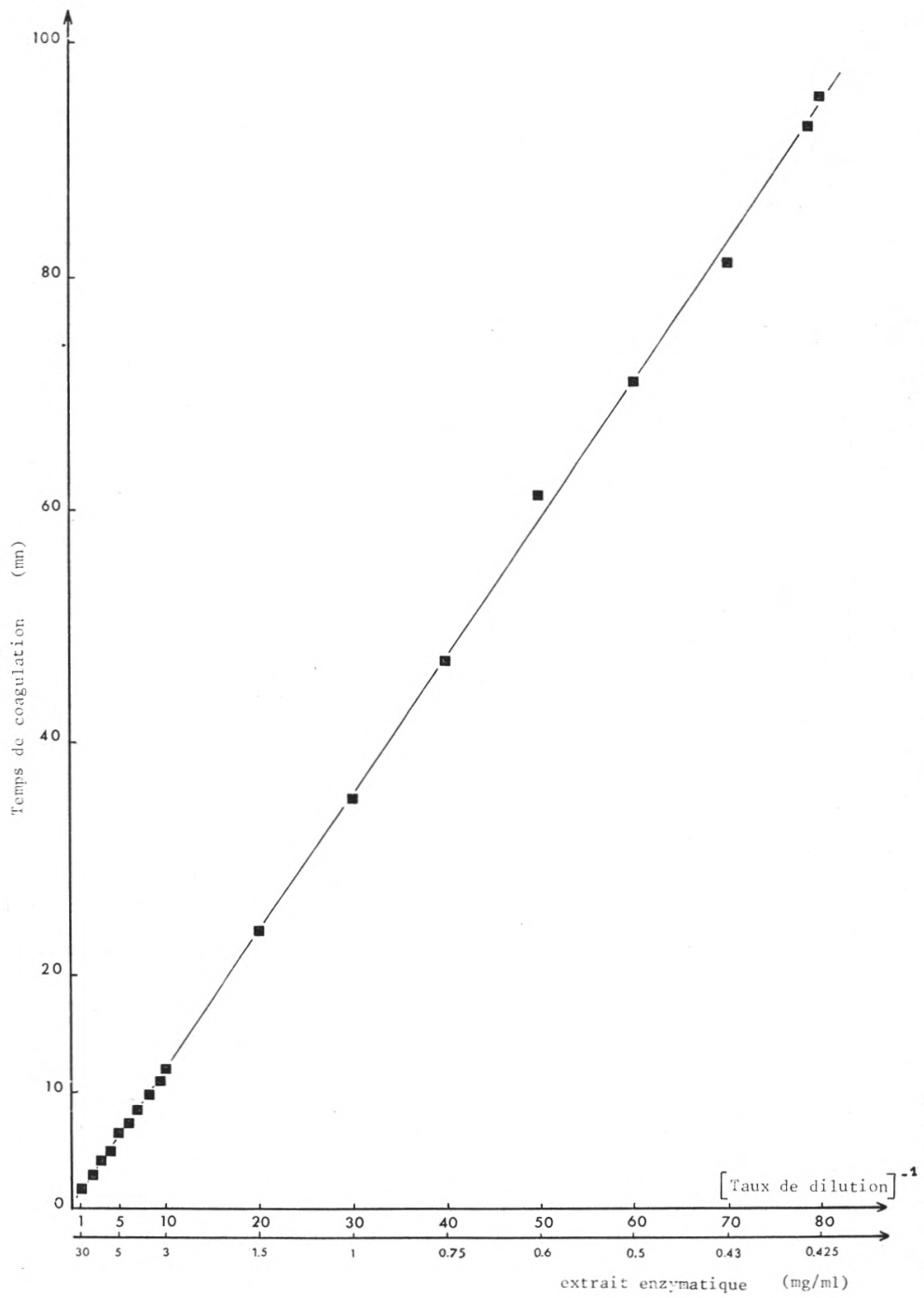

fig. 6

Courbe d'étalonnage : activité coagulante $(\mathrm{mn})$ à $35^{\circ} \mathrm{C}$ en fonction de la concentration en enzyme (solution mère d'extrait enzymatique de $P$. fluorescens LCM 28 P 12 contenant $30 \mathrm{mg} / \mathrm{ml}$ de protéines (moyennes de trois essais). 


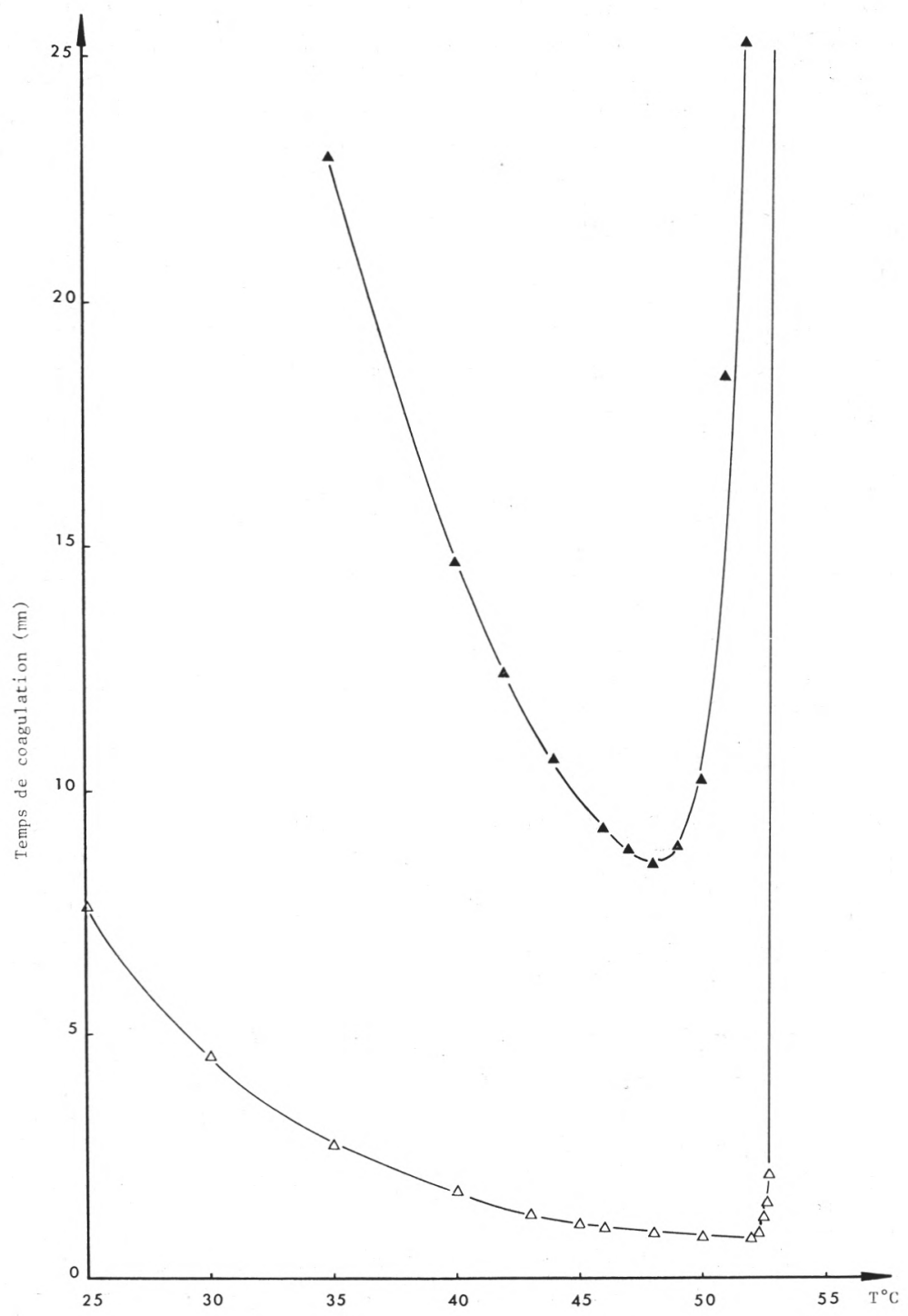

fig. 7

Activité coagulante (mn) en fonction de la température (moyennes de cinq essais)

$\triangle$ Système enzymatique de $P$. fluorescens LCM 28 P 12.

$\Delta$ Système enzymatique de Cytophaga LCM 20 C 2. 
ment retardée $\left(50^{\circ} \mathrm{C}\right.$ et $52^{\circ} \mathrm{C}$ pour les extraits de Cytophaga et $P$. fluorescens) (fig. 7).

Malgré une solution enzymatique quatre fois plus concentrée, l'activité coagulante du système enzymatique de Cytophaga LCM 20 C 2 reste très faible : à la température de $48^{\circ} \mathrm{C}$, elle représente seulement 3 p. 100 de celle du système enzymatique de $P$. fluorescens $28 \mathrm{P} 12$, et c'est la raison pour laquelle son étude ne sera pas poursuivie.

\subsection{Stabilité thermique}

La représentation graphique, selon la loi d'Arrhénius, de l'activité coagulante résiduelle, mesurée à $35^{\circ} \mathrm{C}$, en fonction de la température, montre qu'entre 40 et $100^{\circ} \mathrm{C}$, après $60 \mathrm{mn}$ de chauffage, le système enzymatique coagulant de $P$. fluorescens est très fortement inactivé par deux processus indépendants, l'un agissant à des températures relativement basses, voisines de $45^{\circ} \mathrm{C}$, et l'autre à des températures très élevées, de l'ordre de 90 à $100^{\circ} \mathrm{C}$ (fig. 8).

Cette inactivation entre 44 et $50^{\circ} \mathrm{C}$ semble expliquer, lors de l'étude précédente sur l'activité coagulante en fonction de la température, les retards importants observés dans les temps de coagulation aux températures proches de $50^{\circ} \mathrm{C}$. Après $10 \mathrm{mn}$ de chauffage, l'inhibition du système coagulant est moins prononcée à $90^{\circ} \mathrm{C}$ qu'à $60^{\circ} \mathrm{C}$; ce résultat paradoxal peut s'expliquer si l'on admet que, dans le cas de l'essai à $90^{\circ} \mathrm{C}$, en raison d'un gradient de température plus important, la durée de séjour du système enzymatique dans la zone critique d'inactivation $\left(44-50^{\circ} \mathrm{C}\right)$, est plus courte.

Pour des températures comprises entre 80 et $100^{\circ} \mathrm{C}$, l'inactivation thermique est très importante pendant la première minute du traitement, car 80 à 90 p. 100 du système enzymatique coagulant sont dénaturés à des températures supérieures ou égales à $80^{\circ} \mathrm{C}$, mais la dénaturation totale n'intervient, à $100^{\circ} \mathrm{C}$, que pour des durées de chauffage supérieures à $1 \mathrm{~h}$ (fig. 9).

\subsection{Influence du $\mathrm{pH}$ : Courbe $\mathrm{pH}$ - stabilité}

L'extrait enzymatique de $P$. fluorescens $(7,5 \mathrm{mg} / \mathrm{ml})$ est porté à différentes valeurs de $\mathrm{pH}$, avec $\mathrm{HCl}$ ou $\mathrm{NaOH}(\mathrm{N}$ ou $\mathrm{N} / 10)$, comprises entre $\mathrm{pH} 2,5$ et $\mathrm{pH}$ 12. Après un repos de $2 \mathrm{~h}$ à $4^{\circ} \mathrm{C}, \mathrm{le} \mathrm{pH}$ de la solution enzymatique est réajusté à 7,0 et le test de coagulation est réalisé à $35^{\circ} \mathrm{C}$.

La courbe $\mathrm{pH}$ - stabilité (fig. 10) montre qu'aux valeurs extrêmes de la gamme, $\mathrm{pH} 3$ et $\mathrm{pH} 12$, la stabilité du système coagulant est très réduite, tandis qu'elle n'est pas altérée à la neutralité, entre $\mathrm{pH}$ 6,5 et 7,5 .

Pour la zone de $\mathrm{pH}$ comprise entre 8,75 et 9,70 , nous observons une inhibition importante du pouvoir coagulant qui semblerait être en relation, mais cela reste à démontrer, avec une modification dans l'ionisation du site actif. 


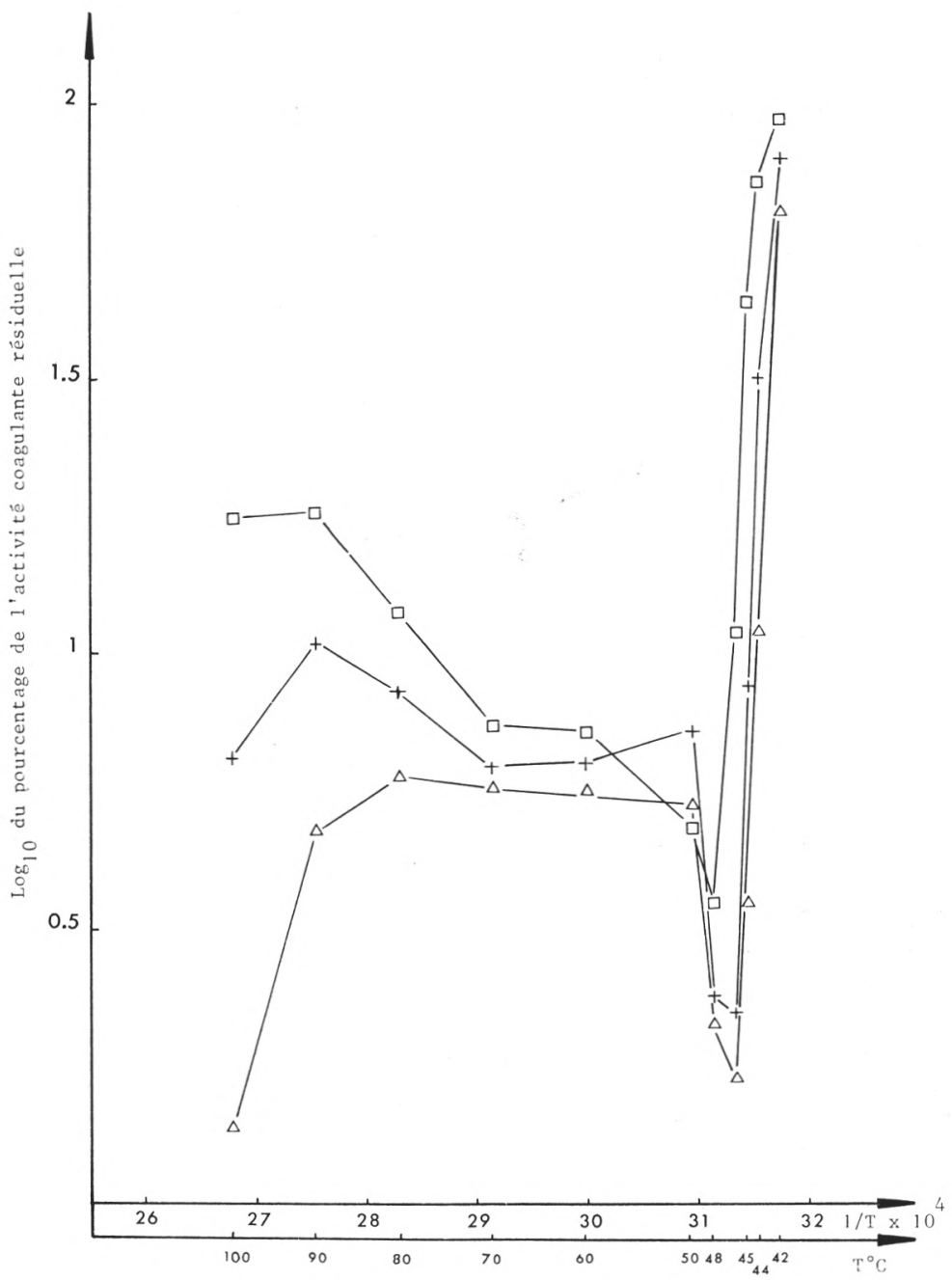

fig. 8

Inactivation thermique du système enzymatique coagulant de $P$. fluorescens LCM 28 P 12 (représentation de la loi d'Arrhénius).

Durées de chauffage : $\square 10 \mathrm{mn} ;+30 \mathrm{mn} ; \triangle 60 \mathrm{mn}$. 


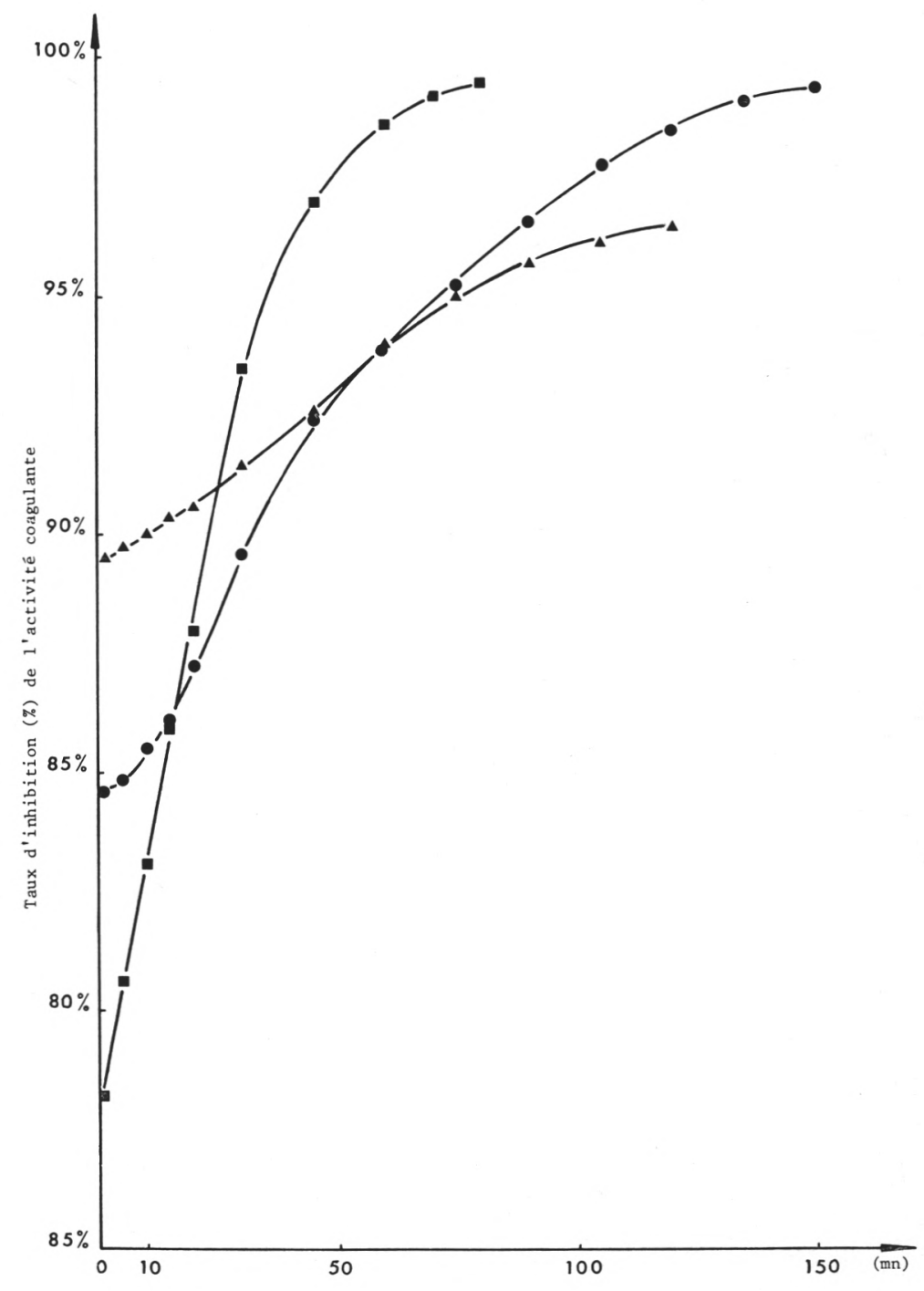

fig. 9

Taux d'inhibition de l'activité coagulante $(\mathrm{mn})$ en fonction des durées de chauffage à différentes températures : $\Delta 80^{\circ} \mathrm{C} ; \bullet 90^{\circ} \mathrm{C}$; $100^{\circ} \mathrm{C}$. 


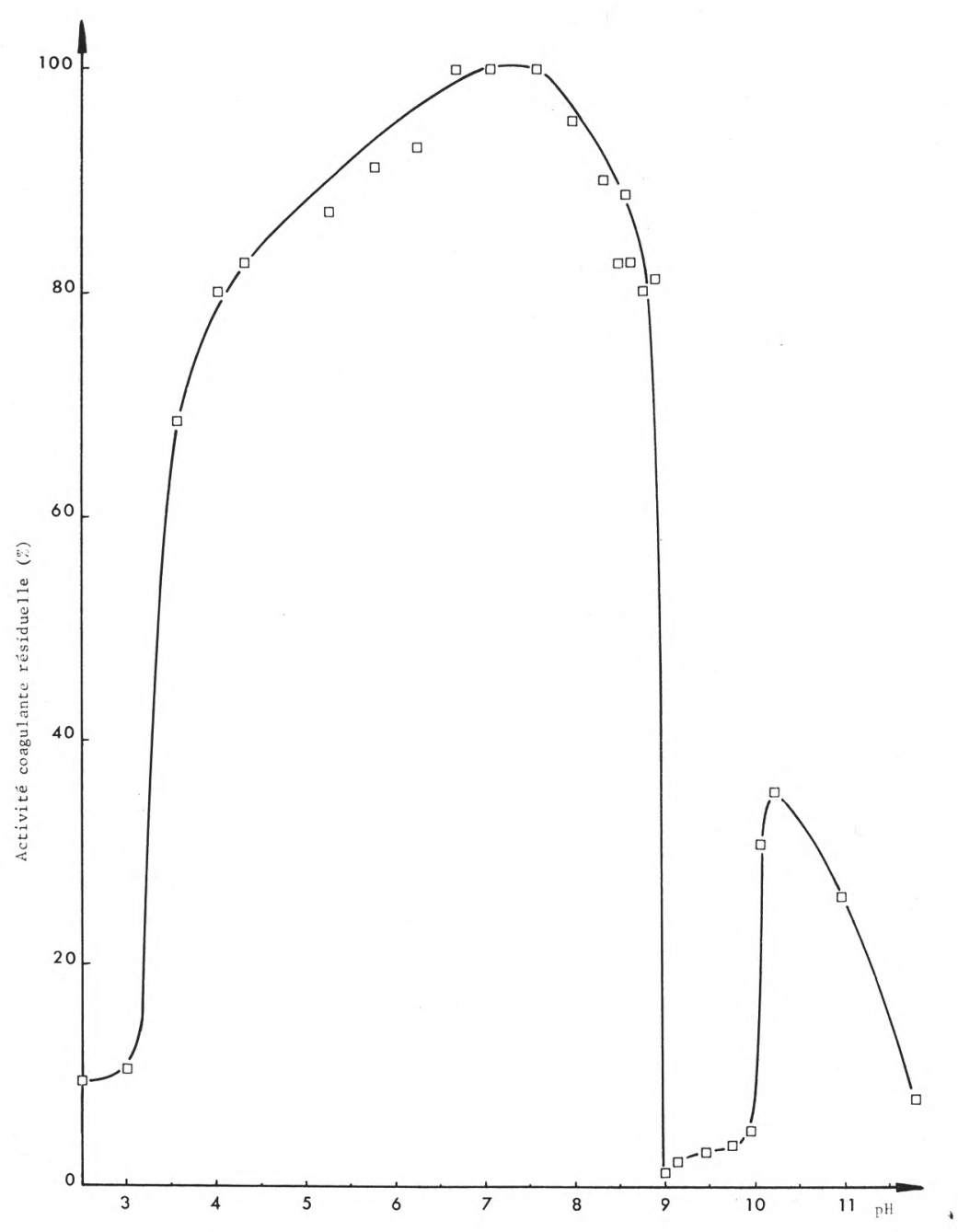

fig. 10

Courbe pH-stabilité du système enzymatique coagulant de $P$. fluorescens LCM 28 P 12.

\subsection{Influence de la concentration en $\mathrm{Ca}^{++}$}

Comme avec l'utilisation de la présure ou d'enzymes d'origine fongique, l'augmentation de la teneur en $\mathrm{Ca}^{++}$du lait entraîne une diminution du temps de coagulation (fig. 11). Le lait Spray utilisé, 


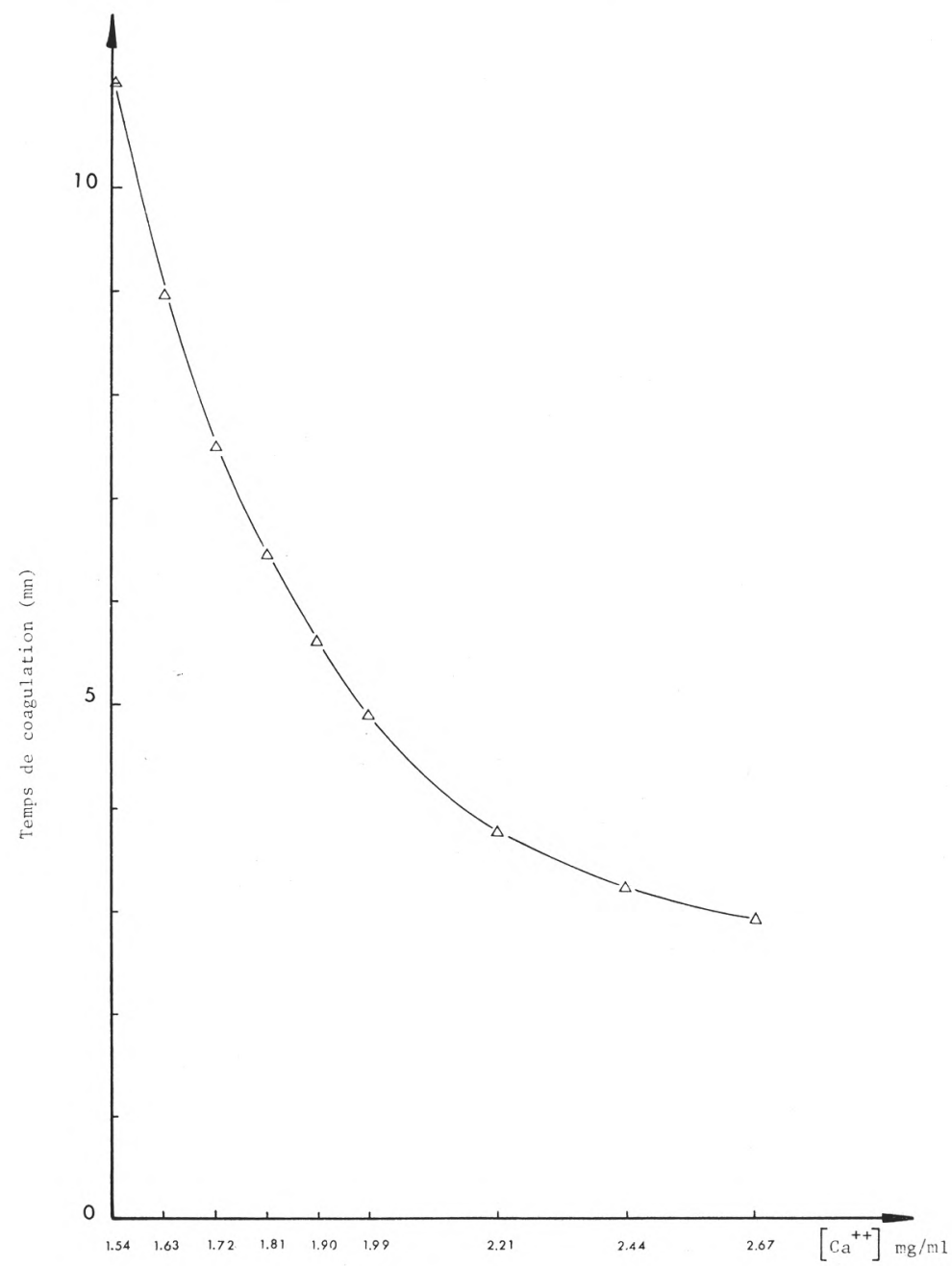

fig. 11

Influence de la concentration en $\mathrm{Ca}^{++}(\mathrm{mg} / \mathrm{ml})$ sur le temps de coagulation ( $\mathrm{mn}^{\prime}$.

fabriqué à des températures relativement basses, contient encore des quantités notables de $\mathrm{Ca}^{++}(1,54 \mathrm{mg} / \mathrm{ml})$.

2.6. Comparaison des propriétés mécaniques des caillés présure et des caillés obtenus à l'aide des protéases de P. fluorescens 28 P 12 
Des solutions enzymatiques contenant par $\mathrm{ml}, 2,9 \mu \mathrm{l}$ de présure, de marque Boll et de force 1/10 000, ou 7,5 mg d'extrait enzymatique donnent, à la température de $35^{\circ} \mathrm{C}$, un temps de coagulation de $5 \mathrm{mn} 10 \mathrm{~s}$.

L'observation en continu des différentes phases de la formation de chaque coagulum est réalisée à l'aide d'un thrombélastographe (marque Thrombocord, La.r.a.). L'examen des thrombodynamogrammes, selon Frentz [20], montre qu'après des temps de coagulation identiques, le caillé réalisé à partir de l'extrait enzymatique de $P$. fluorescens acquiert plus rapidement ses propriétés mécaniques maximales, qui restent cependant plus faibles que celles du caillé présure. La rétraction du coagulum intervient donc plus tôt et les différents paramètres Ir (calculés après 30,60,120 et $180 \mathrm{mn}$ ) montrent qu'elle est plus prononcée (tab. 1).

Le coagulum ainsi réalisé est toujours moins ferme que le caillé présure et subit très rapidement l'action de la protéolyse générale.

TABLEAU 1

Paramètres thrombodynamographiques des caillés

\begin{tabular}{|c|c|c|}
\hline $\begin{array}{c}\text { Extrait enzymatique de } \\
P . \text { fluorescens } \\
(7,5 \mathrm{mg} / \mathrm{ml})\end{array}$ & $\begin{array}{l}\text { Présure } \\
(2,9 \mu \mathrm{l} / \mathrm{ml}\end{array}$ & $\begin{array}{l}\text { Paramètres } \\
\text { thrombodynamo- } \\
\text { graphiques }\end{array}$ \\
\hline $10,30 \mathrm{~mm}$ & $10,30 \mathrm{~mm}$ & $\mathrm{r}$ \\
\hline $10 \mathrm{~mm}$ & $11 \mathrm{~mm}$ & k \\
\hline $35,5 \mathrm{~mm}$ & $46,75 \mathrm{~mm}$ & Am \\
\hline \multirow{2}{*}{55,04} & \multirow{2}{*}{87,8} & \multirow{2}{*}{$\mathrm{Em}=\frac{100 \mathrm{Am}}{100-\mathrm{Am}}$} \\
\hline & & \\
\hline $83 \mathrm{~mm}$ & $145 \mathrm{~mm}$ & $\begin{array}{c}\mathrm{S} \\
\text { Paramètres de rétraction }\end{array}$ \\
\hline \multirow{2}{*}{1,052} & \multirow{2}{*}{1,016} & \multirow{2}{*}{$\operatorname{Ir} 30=\frac{\mathrm{Am}}{\mathrm{A} 30}$} \\
\hline & & \\
\hline 1,127 & 1,039 & $\operatorname{Ir} 60$ \\
\hline 1,291 & 1,087 & Ir 120 \\
\hline 1,578 & 1,126 & Ir 180 \\
\hline
\end{tabular}




\section{Etude de la dégradation de la caséine par électrophorèse en gel de polyacrylamide}

En culture sur lait, les souches $P$. fluorescens $28 \mathrm{P} 12$ et Cytophaga $20 \mathrm{C} 2$, avec des populations initiales de 10800 et 17000 bactéries par $\mathrm{ml}$, dégradent rapidement la caséine $\beta$, alors que la dénaturation de la caséine $\alpha$, plus tardive, reste encore faible après $50 \mathrm{~h}$ d'incubation, respectivement à 20 et à $30^{\circ}$. Après $100 \mathrm{~h}$ d'incubation, nous observons la protéolyse totale des caséines $\beta$ et $\alpha$, avec apparition de fractions ayant une mobilité électrophorétique plus grande. La $\beta$-lactoglobuline ne semble pas être altérée par ces enzymes protéolytiques.

\section{DISCUSSION}

\section{Obtention des systèmes enzymatiques protéolytiques}

Les informations sur la production et les propriétés des systèmes enzymatiques protéolytiques des espèces bactériennes psychrotrophes sont fort peu nombreuses. La majorité des travaux concernent le genre Pseudomonas, et c'est surtout l'espèce $P$. fluorescens, isolée fréquemment de lait cru, qui est la plus étudiée.

Ces différentes recherches ne concordent pas sur le choix de la température et de la durée d'incubation qui permettent l'élaboration maximale d'enzymes protéolytiques.

Peterson et al. [62] trouvent que la production des enzymes de membrane (exoenzymes) est inversement proportionnelle à la température d'incubation, entre 0 et $30^{\circ} \mathrm{C}$, et de nombreuses études indiquent que l'élaboration des protéases, par les bactéries psychrotrophes, est maximale aux environs de $0^{\circ} \mathrm{C}[25,43,54,62]$. Cependant po:ur d'autres chercheurs cette activité augmente avec la température : Juffs [26], en 1976, en travaillant sur les espèces $P$. fluorescens et $P$. aeruginosa observe que l'activité protéolytique par cellule, la plus intense, est obtenue après $7 \mathrm{j}$ de culture, à $20^{\circ} \mathrm{C}$, et qu'elle diminue avec des incubations à $10^{\circ} \mathrm{C}$ et à $5^{\circ} \mathrm{C}$; cette constatation confirme les travaux plus anciens de Vanderzant et Moore [72], Sanvik et Fossum [64], Hurley et al. [23].

Dans notre étude, l'activité maximale se manifeste en phase stationnaire de croissance à $20^{\circ} \mathrm{C}$ pour $P$. fluorescens et à $30^{\circ} \mathrm{C}$ pour Cytophaga. Nous n'avons pu mettre en évidence, comme Peterson et al. [62], en plus des exoprotéines périplasmiques, la présence d'enzymes intracellulaires, mais il est certain que ces deux systèmes coexistent dans nos extraits enzymatiques obtenus après $5 \mathrm{j}$ de culture.

La plupart des chercheurs arrêtent le développement bactérien lorsque l'activité protéolytique, par $\mathrm{ml}$ de substrat, atteint un maximum, d'où des durées d'incubation s'échelonnant entre 2 et 11 
jours $[1,71]$, variables selon la composition du milieu, la température et le taux d'ensemencement choisis. Le système enzymatique de $P$. fluorescens LCM 28 P 12 est extrait après $120 \mathrm{~h}$ d'incubation à $20^{\circ} \mathrm{C}$, barème également retenu par Adams et al. [1].

Le pourcentage de saturation en $\mathrm{SO}_{4}\left(\mathrm{NH}_{4}\right)_{2}$ utilisé lors de l'extraction du système enzymatique, varie aussi très largement ; d'une manière générale la majorité des chercheurs ayant travaillé avec $P$. fluorescens dépassent rarement 65 p. 100 de saturation : 50 p. 100 pour Adams [1], 55 p. 100 pour Mayerhoffer [49], 65 p. 100 pour Barach et al. [7] et White et al. [73], 70 p. 100 pour Malik [44]. Seuls Hurley et al. [23] récupèrent les fractions jusqu'à 85 p. 100 de saturation. Dans nos essais, la quasi-totalité de l'activité enzymatique est concentrée dans la fraction 0-50 p. 100 .

\section{Activité protéolytique}

Les résultats des études précédentes ne permettent pas de définir avec précision les propriétés particulières du système enzymatique protéolytique de l'espèce $P$. fluorescens, car de nombreux paramètres interviennent, certains inhérents à la souche, d'autres dépendant des conditions de production et d'obtention des enzymes, ainsi que des protocoles utilisés lors de la détermination de l'activité protéolytique.

En ce qui concerne la température optimale d'activité enzymatique de l'espèce $P$. fluorescens, de 42 à $43^{\circ} \mathrm{C}$ dans notre étude, elle est de $45^{\circ} \mathrm{C}[1,44]$ ou atteint même $50^{\circ} \mathrm{C}$ [58]. La mesure de cette température est étroitement liée au $\mathrm{pH}$ du substrat et à la durée de la réaction enzymatique et il n'est donc pas étonnant de noter ces différences.

Le système enzymatique de Cytophaga $20 \mathrm{C} 2$ et surtout celui de $P$. fluorescens $28 \mathrm{P} 12$ sont très thermosensibles, et ce dernier est rapidement inactivé à des températures inférieures ou égales à $50^{\circ} \mathrm{C}$. Adams [1] constate également que l'activité des protéases de $P$. fluorescens décroît rapidement au-dessus de $45^{\circ} \mathrm{C}$ et s'annule à $55^{\circ} \mathrm{C}$. Cependant de nombreux chercheurs rapportent des activités résiduelles notables après des traitements thermiques sévères tels que la pasteurisation $[45,61,64]$ ou même la stérilisation U.H.T. (tab. 2). C'est ainsi que le système enzymatique de l'espèce $P$. fluorescens MC 60 de Barach et al. [6], inactivé à un taux de 24,4 p. 100 à $149^{\circ} \mathrm{C}$ pendant $10 \mathrm{~s}$, est détruit à plus de $97,8 \mathrm{p} .100$ après seulement $10 \mathrm{mn}$ de maintien à $55^{\circ} \mathrm{C}$. Speck et Adams [66] pensent que les mécanismes d'altération de l'activité protéolytique qui interviennent aux températures comprises entre 50 et $60^{\circ} \mathrm{C}$, non élucidés, sont différents d'une action thermique.

Les écarts dans les $\mathrm{pH}$ optima des réactions enzymatiques sont plus restreints, car ils sont généralement compris entre $\mathrm{pH} 7$ et pH 8 [27], résultat qui concorde avec celui de notre étude. Les pro- 
TABLEAU 2. - Résistance thermique des protéases des bactéries psychrotrophes

Références bibliographiques

PETERSON, Gunderson (1960) [62]

SANDVIK, Fossum (1963) [64]

HURLEY, GARDNER, VANDERZANT (1963) [23]

MC CASKEY (1967) [43]

Kielwein, Johne, Gerlach (1969) [31]

KISHONTI, SJöSTRÖM (1970) [32]

MAYERHOFER (1971) [47]

THOMAS, DRUCE (1971) [69]

MAYERHOFER, LU, MARSHALL, WHITE (1971) [48]

KNaUt, MeCh (1972) [37]

White, Marshall (1973) [73]

Cheng, Gelda (1973) [11]

MAYERHOFER, MARShaLL, WHITE, LU (1973) [49]

BERGTSSON, GARDHAGE, IsAKSSON (1973) [8]

MALIK, SWANSON (1974) [45]

MaLiK, SWANSON (1975) [46]

KISHONTI (1975) [32]

Adams, Barach, Speck (1975) [1]

BARACH, AdAMS, SPECK (1975) [6]

MaLIK (1976) [44]

COUSINS, SHARPE, LAW (1977) [16]
Sources

P. fluorescens

Pseudomonas species

$P$. fluorescens

Filtrats acellulaires

de Psychrotrophes

( $P$. fluorescens, $P$. punctatum) Genres

Pseudomonas et Aeromonas

60 souches de Psychrotrophes

Pseudomonas spp, Alcaligenes, Aerobacter

P. fluorescens P. 26

Psychrotrophes

Psychrophiles

$P$. fluorescens

P. fluorescens P. 26

Psychrotrophes

P. fluorescens P. 26

Pseudomonas spp

Psychrotrophes (Pseudomonas) $P$. fluorescens (3 souches)

Majorité de $P s$. spp (60 cultures)

Pseudomonas (10 souches) Souche

$P$. fluorescens MC 60

Flore psychrotrophe totale lait cru

P. fluorescens MC 60

P. fluorescens

$P$. fluorescens

téases possèdent encore une stabilité résiduelle importante, supérieure à $85 \mathrm{p} .100$, lorsqu'elles sont placées, pendant $2 \mathrm{~h}$ à $21^{\circ} \mathrm{C}$, dans des tampons qui couvrent la gamme de $\mathrm{pH}$ entre 5 et 10 [7].

Les systèmes protéolytiques de $P$. fluorescens $28 \mathrm{P} 12$ et de Cytophaga 20 C 2 semblent particulièrement bien adaptés au lait, puisqu'ils montrent une très bonne activité (environ 90 p. 100 d'acti- 
Inactivation $100^{\circ} \mathrm{C}-10 \mathrm{mn}$.

Résistent à la pasteurisation.

Inactivation filtrat acellulaire : $28 \mathrm{mn}-50^{\circ} \mathrm{C}, 40 \mathrm{~s}-60^{\circ} \mathrm{C}, 20 \mathrm{~s}-70^{\circ} \mathrm{C}$.

Pas inactivation totale à $62,8^{\circ} \mathrm{C}-82 \mathrm{mn}$.

Résistent à un traitement U.H.T.

$90^{\circ} \mathrm{C}-2 \mathrm{mn}$ : perte de $\leqslant 75$ p. 100 activité initiale.

$130^{\circ} \mathrm{C}-5$ à $10 \mathrm{mn}$, perte de 99 p. 100 activité initiale.

$71,4^{\circ} \mathrm{C}-8,5 \mathrm{~h}$, inactivation enzyme non purifiée.

$100^{\circ} \mathrm{C}-20 \mathrm{mn}$, inactivation totale.

Stabilité à la chaleur : $71,4^{\circ} \mathrm{C}-8,5 \mathrm{~h}$.

$63^{\circ} \mathrm{C}-30 \mathrm{mn}$, inactivation faible.

$75^{\circ} \mathrm{C}-10 \mathrm{mn}$, inactivation $50 \mathrm{p} .100$.

$85^{\circ} \mathrm{C}: 5 \mathrm{mn}$ inactivation $70 \mathrm{p} .100$.

$100^{\circ} \mathrm{C}-5 \mathrm{mn}$, inactivation totale.

$71,4^{\circ} \mathrm{C}-30 \mathrm{mn}$, conservation $71 \mathrm{p} .100$ activité initiale.

Résistent partiellement à $136,7^{\circ} \mathrm{C}-8 \mathrm{~s}$ dans la crème à $10 \mathrm{p} .100$.

D149 $\mathrm{C}=90 \mathrm{~s} ; 120^{\circ} \mathrm{C}-9 \mathrm{mn} \rightarrow$ perte $90 \mathrm{p} .100$ activité.

[nactivation totale en $15 \mathrm{~h}$ à $62,8^{\circ} \mathrm{C} ; 8 \mathrm{~h}$ à $71,4^{\circ} \mathrm{C} ; 9 \mathrm{mn}$ à $121^{\circ} \mathrm{C}$; après $71,4^{\circ} \mathrm{C}$ -

$50 \mathrm{mn}$, conservation 71 p. 100 activité.

Résistent partiellement au traitement U.H.T.

Résistent partiellement à $135^{\circ} \mathrm{C}-3,5 \mathrm{mn}$.

Résistent à $132^{\circ} \mathrm{C}-110 \mathrm{~s}$.

$90^{\circ} \mathrm{C}-20 \mathrm{mn}$ ou $63^{\circ} \mathrm{C}-30 \mathrm{mn}$, gardent 75 p. 100 activité initiale.

$20^{\circ} \mathrm{C}-5 \mathrm{mn}$, conservation 20 p. 100 activité.

$3149^{\circ} \mathrm{C}=90 \mathrm{~s} ; \mathrm{z}=32,5^{\circ} \mathrm{C}$.

$49^{\circ} \mathrm{C}-4 \mathrm{~s}$, inactivation $<10$ p. 100 activité initiale.

Survie à $149^{\circ} \mathrm{C}-10 \mathrm{~s}$.

i5 $5^{\circ} \mathrm{C}-10 \mathrm{mn}$, inactivation 90 p. 100 (en solution tampon).

i5 $5^{\circ}$ C - $60 \mathrm{mn}$, inactivation 96,8 p. 100 ou 70 p. 100 (lait stérile).

Résistent à $132^{\circ} \mathrm{C}-110 \mathrm{~s}$, conservent $44 \mathrm{p} .100$ de leur activité après $100^{\circ} \mathrm{C}-10 \mathrm{mn}$.

Résistent à $140^{\circ} \mathrm{C}-3,5 \mathrm{~s}$.

vité résiduelle) entre $\mathrm{pH} 6,4$ et 6,6 , et pour des concentrations en caséine supérieures ou égales à 2 p. 100 .

\section{Activité coagulante}

Si les travaux de De Beukelar et al. [18] montrent que la caséine $\chi$ n'est pas affectée lors de la protéolyse des fractions $\alpha$ et $\beta$, différentes 
études mentionnent la dégradation de ce colloïde protecteur, donc la coagulation de la caséine par certaines souches psychrotrophes [45], appartenant aux genres Flavobacterium et Aerobacter [33, 34], Pseudomonas [8], et plus particulièrement aux espèces $P$. aeruginosa $[25,55]$ et $P$. fluorescens $[1,8,16,25,40,73)$.

Lors de cultures sur lait écrémé reconstitué, additionné de $\mathrm{Ca}^{++}$, nous observons, après $24 \mathrm{~h}$ d'incubation à $25^{\circ} \mathrm{C}$, chez $P$. fluorescens et plus tardivement chez Cytophaga, la coagulation du substrat et sa protéolyse non spécifique en surface. Nous avons défini certaines propriétés particulières du système enzymatique coagulant de $P$. fluorescens, telles qu'une inactivation rapide pour des températures relativement basses $\left(46^{\circ} \mathrm{C}\right)$, une thermorésistance cependant élevée puisque la dénaturation totale n'intervient à $100^{\circ} \mathrm{C}$ que pour des durées de chauffage supérieures à $1 \mathrm{~h}$, et une très grande stabilité, puisqu'il conserve plus de 90 p. 100 d'activité entre pH 5 et pH 8,5.

L'étude au thrombélastographe de la formation du coagulum à $35^{\circ} \mathrm{C}$, montre que le caillé obtenu par l'action des protéases de $P$. fluorescens acquiert, par rapport au caillé présure, des propriétés mécaniques plus faibles qui diminuent très rapidement en raison d'une activité protéolytique générale intense.

Juffs [25] a utilisé les protéases d'une souche de $P$. fluorescens en fromagerie, mais l'emploi de ces enzymes comme succédané de la présure ne semble pas devoir être retenu, car même une addition à la présure de la protéase de $P$. fluorescens, en très faibles proportions (2 à 17 p. 100), ne permet pas d'obtenir des résultats très concluants [25].

\section{Etude électrophorétique de la dégradation de la caséine}

Le développement des espèces bactériennes caséolytiques, dans le lait, provoque des altérations physicochimiques de la structure des caséines. Les bactéries psychrotrophes dégradent, à des degrés divers, les caséines $\alpha_{s}$ et $\beta[12,14,17,33,46,74]$ et l'espèce $P$. fluorescens protéolyse la caséine $\beta$ plus fortement que la caséine $\alpha[3,18,34,40,56$, 63]. C'est ainsi que l'examen électrophorétique d'une culture sur lait de $P$. fluorescens montre la disparition de la fraction $\beta$ après seulement $24 \mathrm{~h}$ d'incubation, tandis que la libération des composés mobiles $\mathrm{x}$ et $\mathrm{y}$, issus de la dégradation de la caséine $\alpha_{4}$, n'apparaît qu'après $48 \mathrm{~h}$, suivie de la protéolyse générale des différentes fractions [36]. En ce qui concerne les protéines du sérum, De Beukelar et al. [18] et Cousin et al. [15] ne constatent aucune modification, mais Lindqvist et al. [41] signalent, après un stockage de $24 \mathrm{~h}$ à $4^{\circ} \mathrm{C}$, une dénaturation complète des pseudoglobulines et des sérum-albumines et une attaque préférentielle de deux fractions de protéose-peptone plus vulnérables [65]. Kielwein [30] observe que les enzymes protéolytiques de $P$. fluorescens hydrolysent la caséine $\alpha_{s}$ et la $\beta$-lactoglobuline. 


\section{CONCLUSION}

Les systèmes enzymatiques protéolytiques et coagulants des deux souches étudiées, $P$. fluorescens LCM $28 \mathrm{P} 12$ et Cytophaga LCM $20 \mathrm{C} 2$ sont particulièrement bien adaptés au lait, puisqu'ils possèdent des activités maxima pour des concentrations en caséine supérieures ou égales à $2 \mathrm{p} .100$ à des $\mathrm{pH}$ proches de la neutralité. Ces protéases sont encore actives aux températures de réfrigération généralement adoptées à la ferme pour le stockage du lait cru. Avec des laits fortement contaminés, traits et conservés dans de mauvaises conditions d'hygiène, ou avec des cultures expérimentales de bactéries psychrotrophes caséolytiques, la protéolyse de la caséine provoque des modifications indésirables du lait qui sont à l'origine de certaines anomalies de maturation des fromages. Cousin et Marth [12] et Babel [5] observent une diminution du temps de prise en relation avec la prolifération de certaines espèces psychrotrophes, dont les protéases, douées d'activité coagulante, altèrent la structure de la caséine $\%$, facilitant ainsi l'action ultérieure de la présure, et un tel lait peut coaguler pendant un traitement U.H.T. [2]. L'activité des protéases augmente la teneur en fractions azotées solubles du lait cru [59, 75], confère au coagulum des propriétés rhéologiques médiocres, telles qu'un manque de fermeté $[10,60,68]$, une synérèse insuffisante [59], une protéolyse générale intense du caillé [13] qui se traduit par l'apparition d'odeurs désagréables, de goûts amers $[1,4,19,47,65]$ et une diminution des rendements fromagers.

Les niveaux de population associés aux défauts de flaveur varient selon les genres et selon les espèces d'un même genre, mais il convient de souligner qu'ils sont généralement compris entre $1.10^{6}$ et $1.10^{8}$ bactéries par ml. Pour des laits jugés de qualité insatisfaisante sur le plan bactériologique, de telles modifications dans la structure physicochimique peuvent être observées, à des degrés divers, mais pour des laits correctement stockés pendant $48 \mathrm{~h}$ entre 3 et $4^{\circ} \mathrm{C}$, et contenant entre $1.10^{4}$ et $1.10^{5}$ bactéries par $\mathrm{ml}$, aucune altération n'est décelée.

\section{Rés u m é}

Les systèmes enzymatiques protéolytiques bruts de deux souches psychrotrophes, $P$. fluorescens et Cytophaga, isolées de laits crus réfrigérés, sont caractérisés. L'extraction au $\mathrm{SO}_{4}\left(\mathrm{NH}_{4}\right)_{2}$, à 50 p. 100 de saturation, permet de récupérer la totalité de l'activité enzymatique. En utilisant la caséine à 2 p. 100 comme substrat, les deux extraits enzymatiques donnent des réponses sensiblement identiques : température optimale d'activité comprise entre 42 et $44^{\circ} \mathrm{C}$, thermolabilité très importante pour des températures supérieures à $45^{\circ} \mathrm{C}$, 
activités non négligeables aux températures de réfrigération et $\mathrm{pH}$ optima, à $42^{\circ} \mathrm{C}$, compris entre $\mathrm{pH} 7$ et 7,5 .

Sur lait, ces protéases dégradent rapidement la caséine $\beta$, puis plus tardivement la caséine $\alpha$. Une activité coagulante est mise en évidence pour ces deux extraits, mais la dénaturation de la caséine $\%$ par Cytophaga étant très faible, son étude n'est pas poursuivie. Le système enzymatique coagulant de $P$. fluorescens présente une thermolabilité importante pour des températures proches de $46^{\circ} \mathrm{C}$, mais n'est totalement inactivé qu'après $1 \mathrm{~h}$ de chauffage à $100^{\circ} \mathrm{C}$; il est stable entre $\mathrm{pH} 6,5$ et 7,5. Comparativement au caillé présure, le coagulum obtenu avec l'extrait enzymatique de $P$. fluorescens est moins ferme et est rapidement le siège d'une protéolyse générale intense.

\section{S u m m a ry}

The crude proteolytic enzymatic systems of two psychrotrophic strains, $P$. fluorescens and Cytophaga, isolated from refrigerated raw milks, were characterized.

Extraction with $\left(\mathrm{NH}_{4}\right)_{2} \mathrm{SO}_{4}$, at 50 p. 100 saturation, allowed the recovery of the whole of the enzymatic activity. By the use of casein substrate ( 2 p. 100), both enzymatic extracts gave almost identical results: the optimal temperature for the enzymatic activity was between $42^{\circ} \mathrm{C}$ and $44^{\circ} \mathrm{C}$, thermolability was very high at temperatures above $45^{\circ} \mathrm{C}$, lower activities remained at refrigeration temperatures, optimum $\mathrm{pH}$ activity was between $\mathrm{pH} 7$ and 7.5 , at a temperature of $42^{\circ} \mathrm{C}$.

In milk, these proteases quickly degraded the $\beta$-casein and later the $\alpha$-casein. Clotting activity was noted in the case of both extracts, but because the proteolysis of $\chi$-casein by Cytophaga was very weak, this study was not continued. The clotting enzymatic system of $P$. fluorescens was caracterized by a significant degree of thermolability at temperatures around $46^{\circ} \mathrm{C}$, by complete inactivation after 1 hour's heating at $100^{\circ} \mathrm{C}$ and by its optimum stability between $\mathrm{pH} 6.5$ and 7.5. Compared with rennet-curd, the coagulum obtained with the enzymatic extract of $P$. fluorescens was less firm and more quickly and deeply proteolyzed.

\section{Bibliographie}

[1] Adams (D. M.), Barach (J. T.), Speck (M. L.) (1975), - J. Dairy Sci, 58, 6, 828-834.

[2] Adams (D. M.), Barach (J. T.), Speck (M. L.) (1976). - J. Dairy Sci., 59, 5, 823-827.

[3] Annibaldi (S.) (1962). - XVI e Congr. Int. Lait., 13, 545-556.

[4] Atherton (H. V.), Doan (F. J.), Watrous (G. H. Jr.) (1953). - J. Dairy Sci., $36,6,570$, abstr. M 42 . 
[5] Babel (F. J.) (1953), - J. Dairy Sci., 36, 6, 562, abstr. M 12.

[6] Barach (J. T.), Adams (D. M.), Speck (M. L.) (1976). - J. Dairy Sci., 59, 3, 391-395.

[7] BaRach (J. T.), ADAMS (D. M.), SPECK (M. L.) (1976). - Appl. and environmental Microbiol., 31, 6, 875-879.

[8] Bengtsson (K.), Gardhage (L.), Isaksson (B.) (1973). - Milchwissenschaft, $28,8,495-499$.

[9] Berridge (N. J.) (1945). - Biochem. J., 39, 179-186.

[10] Chapman (H. R.), Sharpe (M. E.), LaW (B. A.) (1976). - Dairy Ind., 41, 2, 42-45.

[11] Cheng (W. S.), Gelda (C. S.) (1973). - J. Dairy Sci., 56, 5, 625, abstr. M 16.

[12] Cousin (M. A.), Marth (E. H.) (1977) _ J Dairy Sci., 60, 7, 1042-1047.

[13] Cousin (M. A.), Marth (E. H.) (1977). - J. Dairy Sci., 60, 7, 1048-1056.

[14] Cousin (M. A.), Marth (E. H.) (1977). - J. Dairy Sci., 60, suppl. 1, 34, abstr. D. 3.

[15] Cousin (M. A.), Marth (E. H.) (1977). - J. Dairy Sci., 60, suppl. 1, 34, abstr. D. 2.

[16] Cousins (C. M.), Sharpe (M. E.), Law (B. A.) (1977). - Dairy Ind., 42, 7, 12-17.

[17] De Beukelar (N. J.), Bradley (R. L.), Marth (E. H.) (1975). - J. Dairy Sci., $58,5,785$, abstr. DFR 6.

[18] De Beukelar (N. J.), Cousin (M. A.), Bradley (R. L.), Marth (E. H.) (1977). J. Dairy Sci., 60, 6, 857-861.

[19] Erdman (I. E.), Thornton (H. R.) (1951). - Can. J. Techn., 29, 232-237.

[20] Frentz (R.) (1965). - Le Lait, 45, 447, 489-508.

[21] Gavini (F.), Leclerc (H.) (1975). - Rev. Int. Océanogr. Méd., 37-38, 17-67.

[22] Hoshino (M.) (1973). - J. Jap. Soc. Fd Nutrit., 26, 4, 233-238.

[23] Hurley (W. C.), Gardner (F. A.), Vanderzant (C.) (1963). - J. Fd Sci., 28, 47-54.

[24] Jenness (R.), Koops (J.) (1962). - Neth. Milk Dairy J., 16, 153-164.

[25] Juffs (H. S.) (1974). - Aust. J. Dairy Techn., 29, 2, 74-78.

[26] JufFs (H. S.) (1976). - J. Appl. Bact., 40, 1, 23-32.

[27] Juffs (H. S.), Doelle (H. W.) (1968). - J. Dairy Res., 35, 3, 395-398.

[28] Juffs (H. S.), Hayward (A. C.), Doelle (H. W.) (1968). - J. Dairy Res., 35, 3, 385-393.

[29] Juffs (H. S.), Madsen (O.) (1974). - Aust. J. Dairy Techn., 29, 2, 99-100.

[30] Kielwein (G.) (1975). - Milchwissenschaft, 30, 10, 605-606.

[31] Kielwein (G.), Johne (H.), Gerlach (R.) (1969). - Archiv LebensmittelHyg., 20, 3, 55-61.

[32] Kishonti (E.), Suöström (G.) (1970). - XVIII e Congr. Int. Lait., 1 F, 516.

[33] Kiuru (K.), Eklund (E.) (1970). - Karjantuote, 53, 4, 124-126, Anal.: Dairy Sci. Abstr., 32, 9, 572, abstr. 3816.

[34] Kiuru (K.), EkLund (E.), Gyllenberg (H.), Antila (M.) (1971). - Milchwissenschaft, 26, 3, 138-141 und XVIII ${ }^{\circ}$ Congr. Int. Lait., 1 F, 111 (1970).

[35] Knaut (T.) (1967). - Milchwissenschaft, 22, 5, 289-292.

[36] Knaut (T), BRuderer (G.) (1965). - Milchwissenschaft, 20, 6, 316-318.

[37] Knaut (Т.), Месн (Н.) (1972). - Milchwissenschaft, 27, 3, 167-170.

[38] Kozlova (L. A.) (1974). - Anal.: Dairy Sci. Abstr., 38, 7, 467, abstr. 4393. 
[39] Lacrosse (R.) (1966). - Milchwissenschaft, 21, 5, 278-279.

[40] Law (B. A.), Andrews (A. T.), Sharpe (M. E.) (1977). - J. Dairy Res., 44, 1, 145-148.

[41] Lindovist (B.), Stogards (T.) (1966), - XVII ${ }^{\mathrm{e}}$ Congr. Int, Lait., A, 297-300.

[42] Lowry (O. H.), Rosebrough (N. J.), FarR (A. L.), Randall (R. L.) (1951). J. Biol. Chem., 193, 265-275.

[43] Mc Caskey (T. A.) (1967). - Diss. Abstr. Sect., B 27, 11, 4046.

[44] Malik (A. C.) (1976). - Dissert. Abstr. Int., B 36, 11, 5499-5500.

[45] Malik (A. C.), Swanson (A. M.) (1974), - J. Dairy Sci, 57, 591, abstr. M 54.

[46] Malik (A. C.), Swanson (A. M.) (1975). - J. Dairy Sci., 58, 5, 795, DFR 42.

[47] Mayerhofer (H. J.) (1971). - Dissert. Abstr. Int., B 31, 10, 6158.

[48] Mayerhofer (H. J.), Lu (M.), Marshall (R. T.), White (C. H.) (1971). - J. Dairy Sci., 54, 5, 763, abstr. M 72.

[49] Mayerhofer (H. J.), Marshall (R. T.), White (C. H.), Lu (M.) (1973). - Appl. Microbiol., 25, 1, 44-48.

[50] Mikawa (K.), Hoshino (T,) (1973). - Jap. J. Dairy Sci., 22, 5, A 176 - A 186.

[51] Miller (I.), KANdLER (O.) (1967). - Milchwissenschaft, 22, 7, 435-439.

[52] Millière (J. B.) (1978). - Thèse de Docteur-Ing., Université Nancy I.

[53] Mrllière (J. B.), Veillet-Poncet (L.) (1979). - Le Lait, 49, 581-582, 56-78.

[54] Mocouot (G.), Auclair (J.) (1967). - Rev. Lait. Franç., 239, 21-25.

[55] Morihara (K.) (1963), - Biochim. Biophys. Acta, 73, 113-124.

[56] Murthy (L.), Herreid (E. O.), Mc Whitney (L. R.) (1958). - J. Dairy Sci., $41,10,1324-1341$.

[57] Nakanishi (T.), Tanabe (T.) (1970). - Jap. J. Dairy Sci., 19, 3, A 75 - A 87.

[58] Newton (S. B.) (1965). - Dissert. Abstr., 26, 1, 374.

[59] O'Leary (J.), Hicks (C. L.), Bucy (J.) (1977). - J. Dairy Sci., 60, suppl. 1, 55, abstr. D 51.

[60] Peltola (E.), Vogt (P.) (1959). - XV Congr. Int. Lait., 1, 268-271.

[61] Perron-Lapied (L.), Odet (G.) (1968). - Rev. Lait. Franç., 256, 439-441.

[62] Peterson (A. C.), Gunderson (M. F.) (1960). - Appl. Microbiol., 8, 98-104.

[63] Pürschel (M.), Pollack (C.) (1972). - Nahrung, 16, 5, 451-459.

[64] Sandvik (O.), Fossum (K.) (1963). - Meieriposten, 52, 28, 639-645.

[65] SkeAn (J. D.), Overcast (W. W.) (1960). - Appl. Microbiol., 8, 335-338.

[66] Speck (M. L.), Adams (D. M.) (1976). - J. Dairy Sci., 59, 4, 786-789.

[67] Storgards (T.), Lindovist (B.) (1962). - XVI e Congr. Int. Lait., A, 793-798.

[68] Swartling (P.) (1966). - Fed. Int. Lait., Munich, 3, doc. 35, 18 p.

[69] Thomas (S. B.), Druce (R. G.) (1971). - Dairy Ind., 36, 2, 145-150.

[70] Thomas (S. B.), Thomas (B. F.) (1973). - Dairy Ind., 38, 1, 11-15, part 1, 38, 2, 61-70, part 2.

[71] VAN DER ZANT (W. C.) (1957). - Fd Res., 22, 2, 151-157.

[72] Van der Zant (W. C.), Moore (A. V.) (1955). - J. Dairy Sci, 38, 7, 743-750.

[73] White (C. H.), Marshall (R. T.) (1973). - J. Dairy Sci., 56, 7, 849-853.

[74] Yanagiya (T.), Mikami (M.), Miura (H.) (1973). - J. Agric. Chem. Soc. Japan, 47, 4, 259-266.

[75] Youssef (A. M.), Salama (F. A.), El-Deeb (S. A.) (1975). - Egyptian J. Dairy Sci., 3, 2, 113-122. 